Article

\title{
Norepinephrine and Serotonin Can Modulate the Behavior of the Probiotic Enterococcus faecium NCIMB10415 towards the Host: Is a Putative Surface Sensor Involved?
}

\author{
Rossella Scardaci ${ }^{1, *,+} \mathbb{D}$, Francesca Bietto ${ }^{1,+} \mathbb{D}$, Pierre-Jean Racine ${ }^{2}$, Amine M. Boukerb ${ }^{2} \mathbb{D}$, Olivier Lesouhaitier $^{2}$, \\ Marc G. J. Feuilloley ${ }^{2} \mathbb{D}$, Sara Scutera ${ }^{3} \mathbb{D}$, Tiziana Musso ${ }^{3}$, Nathalie Connil ${ }^{2}$ and Enrica Pessione ${ }^{1}$
}

1 Laboratory of Microbial Biochemistry and Proteomics, Department of Life Sciences and Systems Biology, University of Turin, Via Accademia Albertina 13, 10123 Torino, Italy; francescabietto@gmail.com (F.B.); enrica.pessione@unito.it (E.P.)

2 Laboratory of Microbiology—Bacterial Communication and Anti-infectious Strategies, University of Rouen Normandy, 27000 Evreux, France; racinepierrejean@gmail.com (P.-J.R.); amine.boukerb@univ-rouen.fr (A.M.B.); olivier.lesouhaitier@univ-rouen.fr (O.L.); marc.feuilloley@univ-rouen.fr (M.G.J.F.); nathalie.connil@univ-rouen.fr (N.C.)

3 Laboratory of Immunology, Department of Public Health and Pediatric Sciences, University of Turin, Via Santena 9, 10126 Torino, Italy; sara.scutera@unito.it (S.S.); tiziana.musso@unito.it (T.M.)

* Correspondence: rossella.scardaci@unito.it

+ These authors contributed equally to this work.

Citation: Scardaci, R.; Bietto, F.; Racine, P.-J.; Boukerb, A.M.; Lesouhaitier, O.; Feuilloley, M.G.J.; Scutera, S.; Musso, T.; Connil, N.; Pessione, E. Norepinephrine and Serotonin Can Modulate the Behavior of the Probiotic Enterococcus faecium NCIMB10415 towards the Host: Is a Putative Surface Sensor Involved? Microorganisms 2022, 10, 487. https://doi.org/10.3390/ microorganisms10030487

Academic Editor: Claudio de Simone

Received: 31 December 2021

Accepted: 16 February 2022

Published: 22 February 2022

Publisher's Note: MDPI stays neutral with regard to jurisdictional claims in published maps and institutional affiliations.

Copyright: () 2022 by the authors. Licensee MDPI, Basel, Switzerland. This article is an open access article distributed under the terms and conditions of the Creative Commons Attribution (CC BY) license (https:// creativecommons.org/licenses/by/ $4.0 /)$.

\begin{abstract}
The human gut microbiota has co-evolved with humans by exchanging bidirectional signals. This study aims at deepening the knowledge of this crucial relationship by analyzing phenotypic and interactive responses of the probiotic Enterococcus faecium NCIMB10415 (E. faecium SF68) to the top-down signals norepinephrine (NE) and serotonin (5HT), two neuroactive molecules abundant in the gut. We treated E. faecium NCIMB10415 with $100 \mu \mathrm{M} \mathrm{NE}$ and $50 \mu \mathrm{M} 5 \mathrm{HT}$ and tested its ability to form static biofilm (Confocal Laser Scanning Microscopy), adhere to the Caco-2/TC7 monolayer, affect the epithelial barrier function (Transepithelial Electrical Resistance) and human dendritic cells (DC) maturation, differentiation, and cytokines production. Finally, we evaluated the presence of a putative hormone sensor through in silico (whole genome sequence and protein modelling) and in vitro (Micro-Scale Thermophoresis) analyses. The hormone treatments increase biofilm formation and adhesion on Caco-2/TC7, as well as the epithelial barrier function. No differences concerning DC differentiation and maturation between stimulated and control bacteria were detected, while an enhanced TNF- $\alpha$ production was observed in NE-treated bacteria. Investigations on the sensor support the hypothesis that a two-component system on the bacterial surface can sense 5HT and NE. Overall, the data demonstrate that E. faecium NCIMB10415 can sense both NE and 5HT and respond accordingly.
\end{abstract}

Keywords: biofilm; adhesion; TER; dendritic cells; TNF- $\alpha$; IL-10; hormone sensor

\section{Introduction}

The genus Enterococcus has been the object of several reports questioning its safety when used as a probiotic during the last two decades [1-3]. In addition to starter strains employed in food production [4], biocontrol strains [5], putative [6-8] and approved probiotics commercially available for human and animals' treatment [2,9], several hospital strains displaying both antibiotic resistance and production of virulence factors have been isolated so far $[10,11]$. These are among the most diffused opportunistic nosocomial pathogens involved in severe diseases such as urinary infections, endocarditis, bacteremia, and central nervous system infections [12]. In particular, these bacteria bear in their genomes multidrug resistance genes $[13,14]$ and the so-called pathogenicity island, which 
encodes for several virulence factors, such as proteases, tissue-targeted toxins, or adhesive molecules that mediate aggregation and adhesion to the host [11]. These factors, when present together, constitute a significant threat to human health. Furthermore, both can be transmitted by horizontal gene transfer (HGT) [15]. Hence, a "safe" strain could acquire them from a pathogen, thus turning into a "dangerous" one. In controversial bacteria, as enterococci are, this aspect is particularly challenging, especially in the gut habitat where they usually live $[14,16]$.

A further concern is that environmental conditions can also affect the expression of genome-encoded virulence factors, as demonstrated in Enterococcus faecalis $[10,17,18]$. Since probiotic features can also be affected by environmental modulation of gene expression, investigation on how enterococcal performances are affected by the environment they typically inhabit is a critical concern. In this regard, the human gut becomes an intriguing ecological niche that provides a broad spectrum of stressors. For example, host-derived signals in the gut, such as norepinephrine (NE) and serotonin $(5 \mathrm{HT})$, have been reported to trigger the virulence of some intestinal pathogens including E. faecalis [19-21], but those conditions can also modify the probiotic properties of exogenously administered enterococci [21]. Previous research tested how NE and 5HT can influence the basal physiological features (growth and protein profiles, resistance to bile salts, and antibiotics) of the probiotic E. faecium NCIMB10415 (E. faecium SF68) and its capability to auto-aggregate and form biofilm [22,23]. Curiously, the proteomic results of 5HT treatment suggested that the effects triggered by this molecule could be mediated by a sensor, primarily described as human signal receptors in prokaryotes [24]. Indeed, bacteria have evolved different response mechanisms to host-derived signals, including Two Component Systems (TCS), firstly described for catecholamines in E. coli $[25,26]$. Considering these overall interesting findings, the present study aimed to evaluate the effects of the hormone treatments on the bacterial-host relationship. This interaction mainly involves communication between bacteria and epithelial cells of the intestinal mucosa, but also cross talk with the gut immune system (GALT), especially mediated by dendritic cells (DC) whose dendrites protrude into the intestinal lumen, thus coming into direct contact with gut microbiota $[27,28]$. (Considering that GALT represents a consistent part of our overall immune system, depicting possible effects of the (treated and untreated) strain in study on its performances is of primary importance to corroborate the growing evidence that a healthy immune status is dependent upon a healthy gut microbiota. In particular, Enterococci, both E. faecalis and E. faecium, have been shown to play a crucial role in immune modulation at the gut level $[29,30]$. Thus, we determined if the treatment with both hormones affected $E$. faecium NCIMB10415 ability to colonize the gut mucosa (biofilm formation and adhesion on Caco-2/TC7 cells) or could affect the intestinal barrier (by measuring the transepithelial electrical resistance-TER - as an index of permeabilization of the epithelial cell membrane). Additionally, we attempted to evaluate if the treatments impacted the immune system (IS) responses to E. faecium NCIMB10415 by challenging human DCs with our strain. Finally, in silico analyses and Micro-Scale Thermophoresis have been used to evaluate the implication of a putative sensor for the detected modifications.

\section{Materials and Methods}

\subsection{Media and Growth Conditions}

E. faecium NCIMB10415 (E. faecium SF68) was grown at $37{ }^{\circ} \mathrm{C}$ in static conditions in a rich Chemically Defined Medium (CDM) to ensure highly reproducible results, as reported elsewhere [22]. 100 $\times$ solutions of NE (L-Norepinephrine (+)-bitartrate salt monohydrate-Sigma Aldrich, St. Louis, MO, USA) and 5HT (serotonin hydrochlorideSigma Aldrich) were freshly prepared in CDM, filter sterilized and diluted to obtain a final concentration that would reflect over secretion in the gut, $100 \mu \mathrm{M}$ and $50 \mu \mathrm{M}$, respectively (for further details see [22,23]). For each experiment, except for biofilm formation, treatments, and control conditions, bacteria were harvested at late exponential phase $(\sim 4 \mathrm{~h}$, see $[22,23])$. 


\subsection{Cell Lines}

Human enterocyte-like Caco-2/TC7 (colon adenocarcinoma cells) were grown in $4.5 \mathrm{~g}$ /L glucose Dulbecco's Modified Eagle Medium (DMEM, Lonza, Basel, Switzerland) supplemented with 15\% heat-inactivated fetal bovine serum (FBS, Sigma Aldrich), 1\% penicillin/streptomycin (Sigma Aldrich), and $2 \mathrm{mM}$ glutamine (Sigma Aldrich). Cells were maintained in a humidified incubator at $37{ }^{\circ} \mathrm{C}$ in $5 \% \mathrm{CO}_{2}$ and $95 \%$ air atmosphere, and the medium was replaced thrice a week. Cells were passed after reaching approximately $90 \%$ of confluence. Monocytes were isolated from peripheral blood mononuclear cells (PMBC) obtained from healthy donor buffy coats (through the courtesy of the S.C. Centro Produzione e Validazione Emocomponenti, Torino, Italy) by Ficoll (Biochrom) gradient (Pharmacia Fine Chemicals, Uppsala, Sweden). CD14 ${ }^{+}$were isolated from PBMCs by immune-magnetic selection with CD14 microbeads and magnetic separation columns (MACS monocyte isolation kit from Miltenyi Biotec, Bergisch Gladbach, Germany). This procedure yielded at least $98 \%$ pure monocyte population, as assessed by fluorescenceactivated cell sorter analysis (FACSCalibur, BD Biosciences, Franklin Lakes, NJ, USA). To obtain monocyte-derived DCs, monocytes were cultured for 5 days at $10^{6}$ cells $/ \mathrm{mL}$ in RPMI 1640 medium (Sigma Aldrich) supplemented with 10\% FBS (Sigma Aldrich), 50 ng/mL GM-CSF (Sigma Aldrich) and 20 ng/mL IL-4 (Sigma Aldrich) [31].

\subsection{Confocal Laser Scanning Microscopy (CLSM) Biofilm Formation}

Overnight precultures were diluted to $\mathrm{OD}_{600} 0.1\left(10^{8} \mathrm{CFU} / \mathrm{mL}\right)$ with or without the molecules, and $500 \mu \mathrm{L}$ of each treatment were seeded in triplicate on a glass flat-bottom 24-wells plate (Sensoplate, Greiner Bio-one, Stonehouse, UK). Bacteria were grown for 24 and $48 \mathrm{~h}$ at $37{ }^{\circ} \mathrm{C}$ (for the measurement at $48 \mathrm{~h}$, the medium and the molecules were replaced after $24 \mathrm{~h}$ without perturbing the bacterial biomasses in the biofilms), after which planktonic cells were removed by three washings with sterile $\mathrm{NaCl} 0.9 \%$. Next, the biofilms were stained with $5 \mu \mathrm{M}$ of SYTO ${ }^{\circledR} 9$ green-fluorescent nucleic acid stain (ThermoFisher Scientific, Waltham, MA, USA) for 15 min in the dark, then washed thrice and observed by CLSM (LSM710, Zeiss, Oberkochen, Germany) with at least 4 captures for each well [21]. The results are a medium of ten biological replicates.

\subsection{Adhesion}

Caco-2/TC7 cells were seeded in 24-well culture plates treated for tissue culture and used at the confluence $\left(10^{6} /\right.$ well). On the experiment day, E. faecium NCIMB10415 was harvested by centrifugation $\left(10,000 \times g, 10^{\prime}\right.$, RT) at the late exponential phase after incubation with the molecules and in control conditions. The pellets were concentrated to $10^{10} \mathrm{CFU} / \mathrm{mL}$ in DMEM without FBS and antibiotics, diluted 1:100, counted on plates, and applied on confluent cells monolayers-previously washed with saline solution to remove the antibiotics - for $2 \mathrm{~h}$ (MOI 1:100 eukaryotic cells: bacteria). Caco-2/TC7 were washed twice with $\mathrm{NaCl} 0.9 \%$ to remove non-adherent bacteria, and $500 \mu \mathrm{L}$ of $0.1 \%$ Triton $100-\mathrm{X}$ was added to disrupt the cells. Then, lysates were serially diluted and plated on BHI agar to count the number of adherent bacteria.

\subsection{Transepithelial Electrical Resistance (TER)}

The effect of NE and 5HT on the modulation of the TER induced by E. faecium NCIMB10415 was assessed as described before [8]. In brief, cells were grown on inserts (3 $\mu \mathrm{m}$ pore size) for 21 days to ensure epithelial differentiation. On the experiment day, treated and untreated bacteria recovered after $4 \mathrm{~h}$ of growth were concentrated to $10^{10} \mathrm{CFU} / \mathrm{mL}$ in DMEM without FBS and antibiotics and diluted to $10^{8} \mathrm{CFU} / \mathrm{mL}$. Microbial cells were deposited on Caco-2/TC7 previously washed twice with saline solution to remove traces of antibiotics and incubated till $20 \mathrm{~h}$. TER was measured using a Millicell Electrical Resistance system (Millipore, Bedford, MA, USA) at $\mathrm{T}_{0}, \mathrm{~T}_{4}, \mathrm{~T}_{16}$ and $\mathrm{T}_{20}$, and results were reported as \% of initial TER. 


\subsection{DCs Stimulation}

To study the effects of the treated E. faecium NCIMB10415 on immune cells, we stimulated DCs for $40 \mathrm{~h}$ with HK bacteria and Cell-Free Supernatants (CFSs). Late exponential phase treated and untreated bacterial cultures were centrifuged at $10,000 \times g$ for $10 \mathrm{~min}$ and the CFSs were collected. To prepare the heat-killed (HK) sample, bacterial cells were washed twice, resuspended in PBS to $10^{9} \mathrm{CFU} / \mathrm{mL}$ and heated for $30 \mathrm{~min}$ at $90^{\circ} \mathrm{C}$. Complete loss of cell viability was verified by monitoring colony formation on agar plates. On the day of the experiment, HK bacteria were diluted in RPMI 1640 medium to obtain a bacteria/host ratio 10:1 and deposited on immature DCs, previously seeded at the density of $10^{6}$ cells $/ \mathrm{mL}$. DCs were also challenged with LPS $(100 \mathrm{ng} / \mathrm{mL})$ as costimulatory molecule and with a combination of LPS and HK bacteria $(100 \mathrm{ng} / \mathrm{mL}$ LPS and HK bacteria MOI 10:1). CFSs obtained by centrifugation were neutralized with $1 \mathrm{M}-\mathrm{NaOH}$ to $\mathrm{pH} 7$ and sterilized by filtering at $0.22 \mu \mathrm{m}$ and stored at $-20{ }^{\circ} \mathrm{C}$ until use. For the experiment, CFSs were added to the DC culture medium at a concentration of $10-30 \% v / v$ and incubated with the immature DCs $\left(10^{6}\right.$ cells $\left./ \mathrm{mL}\right)$. After $40 \mathrm{~h}$ incubation, cells and cell supernatants were collected for flow cytometric and cytokine analysis, respectively. Immature DCs incubated with RPMI 1640 medium were used as negative control.

\subsection{Flow Cytometric Analysis and Cytokine Quantification in Culture Supernatants}

DCs were collected after the indicated time of infection and preincubated for $30 \mathrm{~min}$ at $4{ }^{\circ} \mathrm{C}$ in PBS containing $2 \%$ goat serum plus $0.2 \%$ sodium azide and washed twice with $1 \%$ bovine serum albumin (BSA). Then, cells were incubated for $30 \mathrm{~min}$ at $4{ }^{\circ} \mathrm{C}$ with anti-human CD14-FITC (clone REA599 1:50), anti CD1a-APC (clone REA736 1:50), anti CD80-PE (clone REA661 1:50), anti-CD-83-VioFITC (clone REA714 1:100), and the specific REA control (S) antibodies human IgG1 (all purchased from Miltenyi Biotec, Bergisch Gladbach, Germany). Flow cytometry analysis was performed using FACSCalibur (BD Biosciences, NJ, USA) and FlowLogic software (Miltenyi Biotec).

The culture supernatants of DC were assayed to evaluate the pro-inflammatory cytokines TNF- $\alpha$ (DY210, assay range: 15.6-1000 pg/mL), IL-6 (DY206, assay range: 9.4-600 pg/mL), IL-8 (CXCL8) (DY208, assay range: 31.2-2000 pg/mL), and the antiinflammatory cytokine IL-10 (DY217B, assay range: $31.2-2000 \mathrm{pg} / \mathrm{mL}$ ) by DuoSet ELISA kits purchased from R\&D Systems (R\&D System, Minneapolis, MN, USA) and used according to the manufacturer's instructions.

\subsection{Genome Sequencing and Annotation}

E. faecium NCIMB10415 was cultured in CDM medium O/N at $37^{\circ} \mathrm{C}$. Genomic DNA was extracted using the GeneJet genomic DNA purification kit as recommended by the manufacturer (ThermoFisher Scientific), then quality and quantity were assessed using the double-stranded DNA (dsDNA) high-sensitivity kit on a Qubit fluorometer (ThermoFisher Scientific) and $1 \%$ agarose gel electrophoresis. Sequencing libraries were prepared using the Nextera XT reagent kit (Illumina, San Diego, CA, USA) according to the manufacturer's recommendations. Sequencing was performed by the genomics platform of the Laboratory of Microbiology-Bacterial Communication and Anti-infectious Strategies (CBSA) (Rouen Normandy University, Evreux, France) using an Illumina MiSeq system with a $2 \times 250-b p$ paired-end read protocol. Default parameters were used for all software tools unless otherwise noted. TrimGalore v.0.6.2 [32] was used for reads trimming, and read quality was checked with FastQC v.0.11.9 [33]. Raw paired-end reads were assembled de novo with Unicycler v.0.4.7 [34], and assembly metrics were calculated using QUAST v.5.0.0 [35]. Structural gene prediction and functional annotation were carried out using the Prokka pipeline v.1.14.0 [36].

\subsection{Putative Sensor Sequence Screening and Alignment}

We used the Prokka annotation (faa file) to retrieve the putative adrenergic receptor in E. faecium NCIMB10415 genome sequence, based on sequence identity/coverage 
comparison to QseC from E. coli $\mathrm{K} 12$ and VicK (WalK) previously found in E. faecalis [21]. CLUSTALX2 v.2.1 was used for multiple sequence alignments of the obtained protein sequence and that from E. coli K12, E. faecalis OB15, E. faecalis ATCC $19433^{\mathrm{T}}$ and E. faecium NCTC7171 ${ }^{\mathrm{T}}$. The alignment file was visualized with Jalview 2 [37].

\subsection{Structure Modeling and Docking}

The sequence annotated in the E. faecium NCIMB10415 genome as VicK (WalK) was analyzed with the online server PSIPRED to predict its secondary structure and subcellular localization (http:/ / bioinf.cs.ucl.ac.uk/psipred (accessed on 20 October 2020)) [38]. Comparative 3D modeling was realized with Raptor X (http://raptorx.uchicago.edu/ StructurePrediction/ (accessed on 17 November 2020)), GalaxyWEB (http:/ / galaxy.Seoklab. Org / (accessed on 17 November 2020)) [39] and MODELLER (https:/ / salilab.org/modeller/ (accessed on 17 November 2020) [40]. The models generated by MODELLER were submitted to the energy function DOPE, and QMEAN (https: / swissmodel.expasy.org/qmean/ (accessed on 24 November 2020)) was used to validate a model among the others [41].

Potential ligand interactions (NE, 5HT, phentolamine, and propranolol) were investigated in silico by the molecular docking technique using the predicted structure of the putative adrenergic sensor of E. faecium NCIMB10415. Essential hydrogen atoms, Gasteiger charges, and solvation parameters were added with the aid of AutoDock tools. Affinity (grid) maps of 80 - by 80 - by $80-\AA ̊$ grid points and $0.375-\AA ̊$ spacing were generated using the Autogrid program [42]. AutoDock parameter set- and distance-dependent dielectric functions were used to calculate the van der Waals and electrostatic terms, respectively. Docking simulations were made using the Genetic Algorithm (GA). The structure of NE (CID: 439260), 5HT (CID: 160436), phentolamine (CDI: 5775), and propranolol (CID: 4946) were downloaded from PubChem (http:/ / www.ncbi.nlm.nih.gov/pcc (accessed on 30 November 2020)) in SDF and converted to PDB through PyMOL (http:/ / www.pymol. org/ (accessed on 30 November 2020)).

\subsection{VicK (WalK) Expression and Purification}

To express E. faecium NCIMB10415 VicK (WalK) in E. coli, a synthetic codon-optimized gene was prepared and cloned into the NdeI and BamHI restriction sites of the pET-15b vector, which carries an N-terminal His $\bullet \mathrm{Tag}^{\circledR}$ and resistance to Amp (GenScript Biotech, Piscataway, NJ, USA). Competent $E$. coli BL21 were then transformed with this vector and induced with $0.5 \mathrm{mM}$ IPTG for $4 \mathrm{~h}$ in agitation $(100 \mathrm{rpm})$ and $25^{\circ} \mathrm{C}$. The cells were cooled in ice, then harvested by centrifugation at $4000 \times \mathrm{g}$ for $20 \mathrm{~min}$ at $4{ }^{\circ} \mathrm{C}$ and washed with $20 \mathrm{mM}$ Tris- $\mathrm{HCl} \mathrm{pH}$ 8.0. Next, cells were lysed by sonication and clarified by centrifugation at $4000 \times g$ for $20 \mathrm{~min}$. Finally, the protein was extracted with $1 \%$ dodecyl maltoside (DDM, Applichem Reagents, Darmstadt, Germany) and purified by Immobilized Metal Affinity Chromatography (IMAC). In detail, a 1 mL HiTrap TALON ${ }^{\circledR}$ crude column (Cytiva, Marlborough, MA, USA) was preconditioned with seven volumes of BW buffer ( $50 \mathrm{mM}$ sodium phosphate buffer $\mathrm{pH} 7,300 \mathrm{mM} \mathrm{NaCl}, 5 \%$ glycerol, $20 \mathrm{mM}$ imidazole $\mathrm{pH} \mathrm{8,1 \%}$ DDM), then the whole lysate was loaded at $0.1 \mathrm{~mL} / \mathrm{min}$ and washed with 20 volumes of BW buffer at $0.5 \mathrm{~mL} / \mathrm{min}$. To increase its purity, VicK (WalK) was step-eluted with an increasing concentration of imidazole (Sigma-Aldrich) as follows: BW Buffer was supplemented with $60 / 80 / 100 / 120 / 150 \mathrm{mM}$ of imidazole, each solution was applied for 2 column volumes at $0.25 \mathrm{~mL} / \mathrm{min}$, and $0.5 \mathrm{~mL}$ fractions were collected (total of 20). The protein was concentrated using a Vivaspin 20 centrifugal concentrator (Sartorius, Göttingen, Germany; 50-kDa molecular mass cutoff) at $4{ }^{\circ} \mathrm{C}$ and stored at $-80^{\circ} \mathrm{C}$.

\subsection{Micro-Scale Thermophoresis (MST)}

Micro-Scale Thermophoresis was performed as described previously [43], with few modifications. VicK (WalK) was labeled using the RED-NHS labeling kit (NanoTemper Technologies, München, Germany). The labeling reaction was performed according to the manufacturer's instructions in the supplied labeling buffer, applying a concentra- 
tion of $15 \mu \mathrm{M}$ protein (molar dye: protein ratio $\sim 6: 1$ ) at room temperature for $30 \mathrm{~min}$. The excess of dye was removed by washing $(50 \mathrm{mM}$ Tris- $\mathrm{HCl} \mathrm{pH} \mathrm{7,} 300 \mathrm{mM} \mathrm{NaCl}$, $5 \%$ glycerol, $0.5 \%$ Tween-20) in Amicon ${ }^{\circledR}$ Ultra Centrifugal Filters (Millipore) at 14,000 $\times g$ for $20 \mathrm{~min}$, for three times. The dye/protein ratio was determined using photometry at 650 and $280 \mathrm{~nm}$. VicK (WalK) was adjusted to $7.5 \mathrm{nM}$ with the same buffer. A series of $16 \mathrm{NE}$ and 5HT 1:1 dilutions was prepared in the identical buffer, producing ligand concentrations ranging from $5 \mathrm{mM}$ to $152.6 \mathrm{nM}$. For thermophoresis analysis, each ligand dilution was mixed with one labelled sensor volume, leading to a final concentration of VicK (WalK) of $3.75 \mathrm{nM}$ and final ligand concentrations at half of the ranges above. Approximately $4 \mu \mathrm{L}$ of each solution was filled into Monolith NT standard treated capillaries (NanoTemper Technologies $\mathrm{GmbH}$ ). Thermophoresis was measured using a Monolith NT.115 pico instrument (NanoTemper Technologies $\mathrm{GmbH}$ ) at room temperature with 5-s/30-s/5-s laser off/on/off times, respectively. Instrument parameters were adjusted with $50 \%$ LED power and $60 \%$ MST power. Data from three independently pipetted measurements were analyzed (NT.Analysis software version 1.5.41; NanoTemper Technologies). Following data analysis, the thermophoresis signals were fitted to the formula for $\mathrm{K}_{\mathrm{D}}$ from the law of mass action:

$\mathrm{f}(\mathrm{c})=\frac{\text { unbound }+(\text { bound }- \text { unbound }) \times\left([\mathrm{VicK}]+\mathrm{c}+\mathrm{K}_{\mathrm{D}}-\sqrt{\left(\left([\mathrm{VicK}]+\mathrm{c}+\mathrm{K}_{\mathrm{D}}\right)^{2}-(4 \times[\mathrm{VicK}] \times \mathrm{c})\right.}\right)}{2 \times[\mathrm{VicK}]}$

where $f(c)$ is the observed thermophoresis signal, "unbound" is the signal in the absence of ligand (normalized to 0 ), "bound" is the signal at infinite ligand concentration, c is the concentration of ligand in the same units as VicK (WalK) concentration, and $K_{D}$ is the dissociation constant.

\subsection{Statistical Analysis}

All experiments were performed at least three times independently. Statistical data analyses were carried out with GraphPad Prism 9 using a two-tailed $t$-test. Significance was considered at ${ }^{* * *} p<0.0001,{ }^{* * *} p<0.001,{ }^{* *} p<0.01,{ }^{*} p<0.05$. Data are expressed either as mean \pm standard error (SEM) or \pm standard deviation (SD).

\section{Results}

\subsection{Biofilm}

Our group already assessed the biofilm formation ability of E. faecium NCIMB10415 with the crystal violet method in control and stimulated conditions, and both molecules caused a significant enhancement of biomasses after the treatment [22,23]. The CLSM technique was chosen to validate the results obtained with the CV staining since this method is not considered precise. Biofilms were grown for $24 \mathrm{~h}$ (results not shown as no significant differences were observed) and $48 \mathrm{~h}$ (medium and molecule replacement) on glass surfaces, then their biovolumes, average and maximum thickness were analyzed. Figure 1 and Table 1 illustrate and summarize how NE and 5HT affected our strain's capability to form biofilms. The hormones have augmented all the three parameters; in detail, the treatment with $100 \mu \mathrm{M}$ NE enhances the three of them by about $50 \%$, while $50 \mu \mathrm{M} 5 \mathrm{HT}$ increases twofold the biovolume and the maximum thickness with respect to the control, while the average thickness is augmented by about $40 \%$. These results strongly confirm the $\mathrm{CV}$ assay outcomes concerning the boosting effect of the molecules and its measurement; indeed, $5 \mathrm{HT}$ shows a more intense effect compared to NE, precisely as demonstrated with the CV test $[22,23]$. 


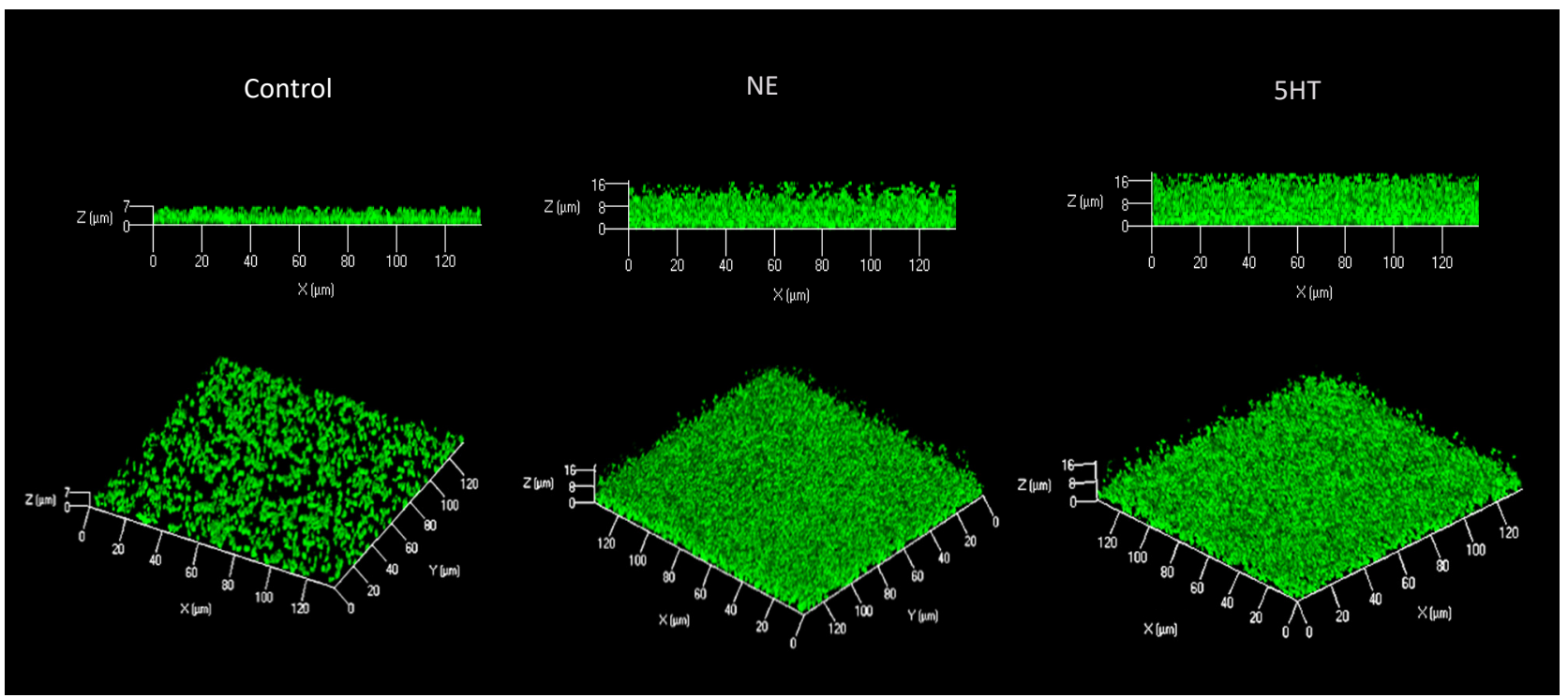

Figure 1. Effect of the treatment of E. faecium NCIMB10415 with $100 \mu \mathrm{M}$ NE and $50 \mu \mathrm{M} 5 \mathrm{HT}$ for $48 \mathrm{~h}$ on biofilm formation on glass surface, measured by CLSM. Both treatments increase the biofilm volume and thickness.

Table 1. Effect of the treatment of E. faecium NCIMB10415 with $100 \mu \mathrm{M}$ NE and $50 \mu \mathrm{M} 5 \mathrm{HT}$ for $48 \mathrm{~h}$ on biofilm formation (biovolume, average thickness, and maximum thickness) on glass surface, measured by CLSM. Both treatments increase the biofilm volume and thickness. The results are expressed $\pm \mathrm{SD}^{* * *} p \leq 0.001,{ }^{* *} p<0.01,{ }^{*} p<0.05$.

\begin{tabular}{cccc}
\hline Treatment & $\begin{array}{c}\text { Biovolumes } \\
\left(\mu \mathbf{m}^{3} / \boldsymbol{\mu m}^{2}\right)\end{array}$ & Average Thickness $(\boldsymbol{\mu m})$ & Maximum Thickness $(\boldsymbol{\mu m})$ \\
\hline Control & $0.63 \pm 0.27$ & $1.4 \pm 0.8$ & $13.2 \pm 2.3$ \\
\hline $100 \mu \mathrm{M} \mathrm{NE}$ & $0.98 \pm 0.28^{* *}$ & $2.3 \pm 1.0^{*}$ & $18.6 \pm 4.1^{* * *}$ \\
\hline $50 \mu \mathrm{M} 5 \mathrm{HT}$ & $1.24 \pm 0.48^{* *}$ & $3.0 \pm 1.2^{* * *}$ & $18.4 \pm 4.1^{* * *}$ \\
\hline
\end{tabular}

\subsection{Adhesion on Caco-2/TC7 Cells}

As it is a predictive sign of the probiotic behavior, the adhesion on Caco-2/TC7 cells (a reliable in vitro model of adhesion on mucosal gut tissues [44-46]) was investigated by applying hormone-treated and untreated E. faecium NCIMB10415 on monolayers for $2 \mathrm{~h}$ and then counting adherent bacteria. As illustrated in Figure 2, NE doubled up the capacity to adhere to this model of enterocytes, while $5 \mathrm{HT}$ enhanced the adhesion by about $30 \%$; however, this modulation was not significant.

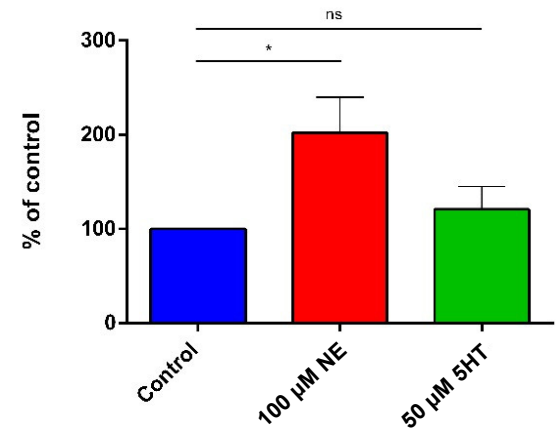

Figure 2. E. faecium NCIMB10415 adhesion on Caco-2/TC7 cells in control condition (blue) or stimulated with $100 \mu \mathrm{M}$ NE (red) or $50 \mu \mathrm{M} 5 \mathrm{HT}$ (green). Treatment with $100 \mu \mathrm{M}$ NE increases the bacterial adhesion. The results are represented as $\%$ of control \pm SEM. ${ }^{*} p<0.05$; ns: not significant. 


\subsection{Effect on the Epithelial Barrier Function (TER on Differentiated Caco-2/TC7 Cells)}

$\mathrm{NE}$ and 5HT modulation of the probiotic efficacy in optimizing the epithelial barrier function was studied, after 4, 16 and $20 \mathrm{~h}$ of treatment on differentiated Caco-2/TC7, with the measurement of the TER. Even if the probiotic started slightly to enhance the TER values at $\mathrm{T}_{4}$, the differences observed were not significant till $20 \mathrm{~h}$ of treatment (Figure 3 and Supplementary Figure S1). Moreover, the treatment with both molecules boosted its capability to modulate the integrity of the intestinal barrier. Specifically, at $\mathrm{T}_{20}$ the TER was increased by about $30 \%, 50 \%$, and $60 \%$, respectively, by the untreated, $100 \mu \mathrm{M} \mathrm{NE}$ and $50 \mu \mathrm{M} 5 \mathrm{HT}$ treated bacteria compared to the negative control.

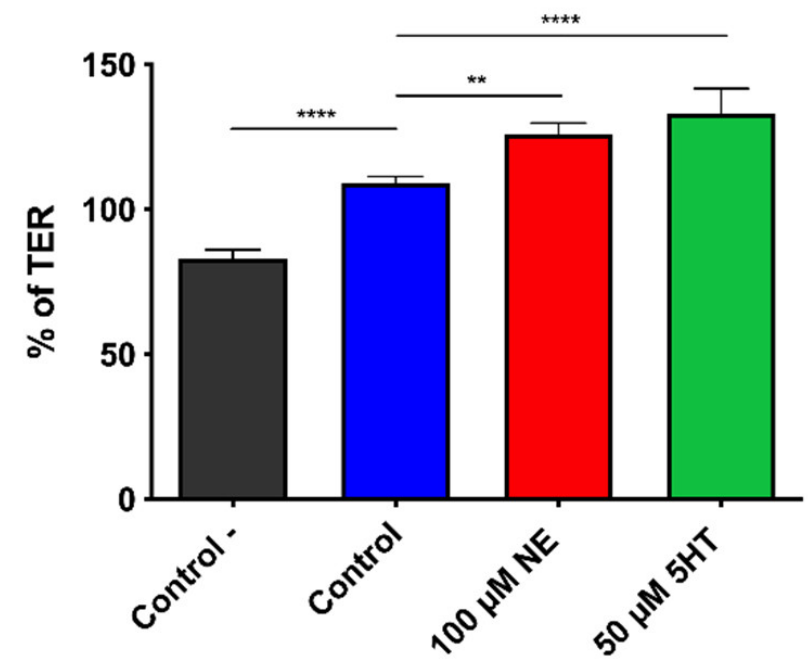

Figure 3. Modulation of Caco-2/TC7 TER after $20 \mathrm{~h}$ exposure to E. faecium NCIMB10415 in control conditions (blue) or treated with $100 \mu \mathrm{M} \mathrm{NE}$ (red) or $50 \mu \mathrm{M} 5 \mathrm{HT}$ (green). Both treatments of the bacteria improve the TER compared to the control condition. In the bar chart is presented also the $\%$ of initial TER for the untreated Caco-2/TC7 cells as 'Control-' (black). Results are expressed as \% of initial TER \pm SEM. ${ }^{* * * *} p \leq 0.0001,{ }^{* *} p<0.01$.

\subsection{Immune Modulation}

To assess the possible immune modulation exerted by 5HT- and NE-treated bacterial cells on DC, we tested the effects of CFSs and living bacteria after growth in stimulated and control conditions. E. faecium NCIMB10415 CFSs did not significantly affect DC maturation (d., and the experiment performed with living bacterial cells was unsuccessful since acidification produced during lactic fermentation damaged the DC. Therefore, we decided to stimulate dendritic cells with hormone-treated and untreated HK bacteria. After $40 \mathrm{~h}$ of coincubation, DCs and their supernatants were collected for flow cytometric and cytokine analysis, respectively.

\subsubsection{Differentiation and Maturation}

We analyzed the expression of DC differentiation and maturation markers after challenging DC with $\mathrm{HK} / \mathrm{Control}, \mathrm{HK} / \mathrm{NE}$ or $\mathrm{HK} / 5 \mathrm{HT}$, alone and in the presence of the costimulatory molecules (LPS). The differentiation of DC was assessed by flow cytometry using the DC marker CD1a and the monocyte marker CD14, whereas the markers CD80 and CD83 were evaluated to ascertain DC maturation. The overall results are summarized in Figure 4 . As expected, in the control DC, we found a high percentage of CD1a ${ }^{+} / \mathrm{CD}_{14}{ }^{-}$, (about $70 \%$ ), a low percentage of $\mathrm{CD}^{+} \mathrm{a}^{+} / \mathrm{CD} 14^{+}(25 \%)$, and the absence of CD1a ${ }^{-} / \mathrm{CD} 14^{+}$ (less than $2 \%$ ). In the presence of all the tested stimuli, we observed a significant increase in the percentage of $\mathrm{CD} 1 \mathrm{a}^{+} / \mathrm{CD} 14^{-}$, in parallel with a decrease in $\mathrm{CD} 1 \mathrm{a}^{+} / \mathrm{CD} 14^{+}$, compared to control conditions (Figure 4a). We next analyzed both CD80 and CD83 expression in terms of the percentage of positive cells as markers of maturation of DC. As shown in Figure $4 \mathrm{~b}$, a similar increase in the percentage of CD80-positive cells over control DC was 
observed in both HK/Control, HK/NE, and HK/5HT-treated DCs. CD80 expression was increased to the same extent following LPS stimulation and was not affected by costimulation with bacteria. Similar results were obtained for the percentage of CD83-positive cells (Figure 4c).

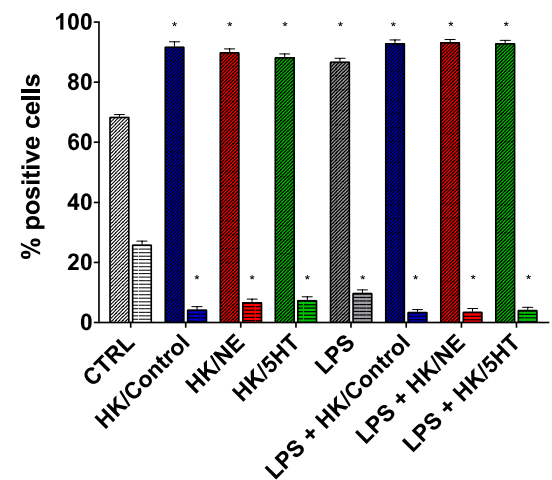

作 $\mathrm{CD} 1 \mathrm{a}^{+} / \mathrm{CD} 14$

彗 $\mathrm{CD} 1 \mathrm{a}^{+} / \mathrm{CD} 14^{+}$

(a)

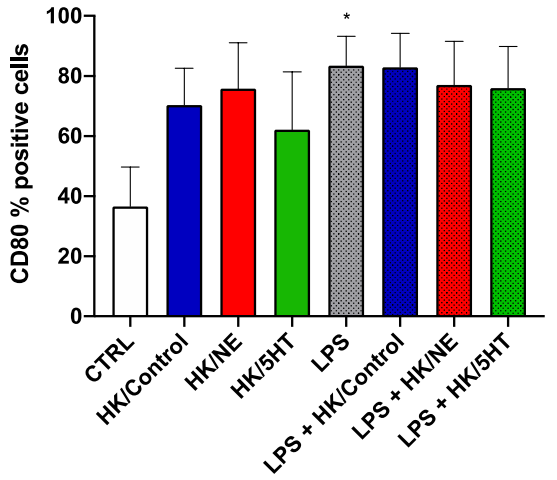

(b)

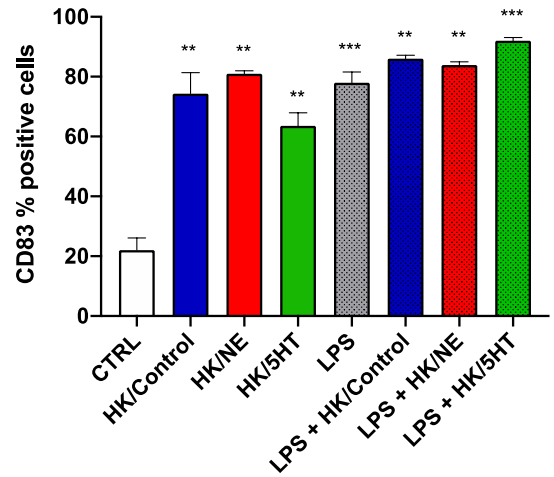

(c)

Figure 4. DC differentiation and activation after $40 \mathrm{~h}$ incubation with $\mathrm{HK} / \mathrm{Control}$ (blue), HK/NE (red) and HK/5HT (green) (a) \% of positive cells \pm SEM displaying CD1a ${ }^{+} / \mathrm{CD}_{14}^{-}$(oblique-line pattern) and $\mathrm{CD} 1 \mathrm{a}^{+} / \mathrm{CD} 14^{+}$(straight-line pattern) phenotype as markers of differentiation; (b) \% of CD80 and (c) \% of C83 positive cells as markers of maturation (LPS cotreatment is presented in dot pattern). Untreated DCs represent the negative control (CTRL) ${ }^{* * *} p \leq 0.001,{ }^{* *} p<0.01,{ }^{*} p \leq 0.05$ to CTRL.

\subsubsection{Cytokine Quantification in Culture Supernatants}

The effect of control, $100 \mu \mathrm{m}$ NE and $50 \mu \mathrm{M}$ 5HT-treated HK bacteria on DC cytokine output was then investigated. Due to high variability among samples (originated from different donors), the results are expressed as a ratio of control (CTRL) conditions. Regarding pro-inflammatory cytokines, Figure 5 shows that the challenge with HK/Control, $\mathrm{HK} / \mathrm{NE}$ and HK/5HT alone induced a slight production of TNF- $\alpha$, IL-6, and IL- 8 compared with unstimulated DC. However, the amounts of all three cytokines are lower than those obtained in LPS-treated DC, which are $15.1 \pm 3.2 \mathrm{ng} / \mathrm{mL}, 10.5 \pm 2.3 \mathrm{ng} / \mathrm{mL}$, and $70.6 \pm 14.2 \mathrm{ng} / \mathrm{mL}$, respectively, for TNF- $\alpha$, IL-6, and IL-8. The simultaneous exposure to HK/Control and LPS did not significantly impact LPS-induced IL-6 and IL-8, while an increase in TNF- $\alpha$ was observed and TNF- $\alpha$ production is enhanced by about two-fold by bacteria treated with NE (Figure 5a). 5HT treatment appears to have no significant effects on cytokine production. 


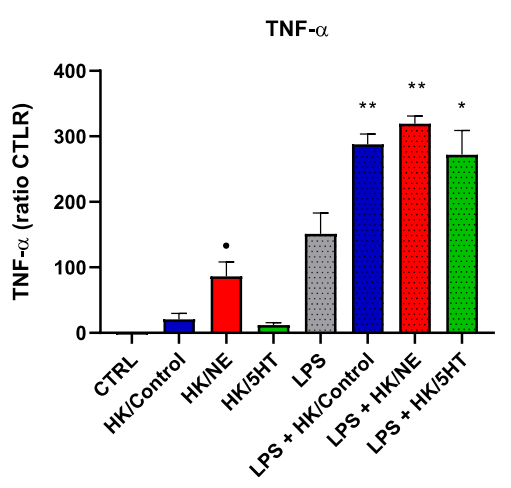

(a)

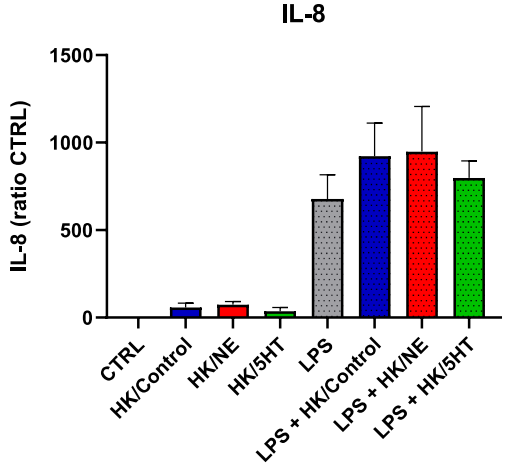

(c)

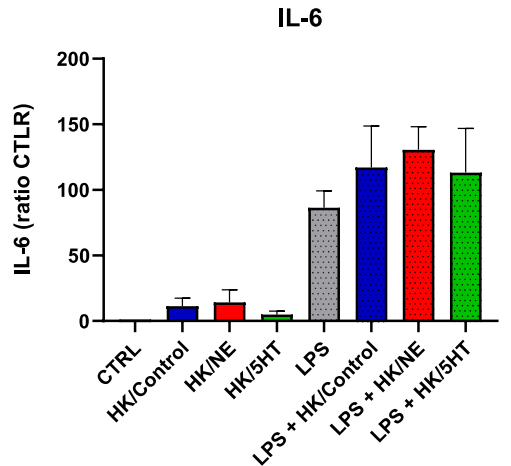

(b)

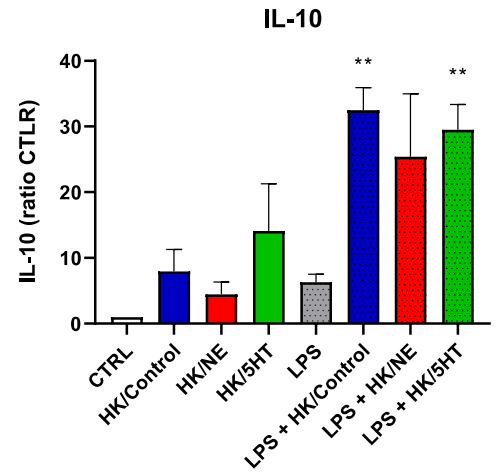

(d)

Figure 5. Cytokines' quantification in DCs culture supernatant after $40 \mathrm{~h}$ incubation with HK/Control (blue), HK/NE (red) and HK/5HT (green). Untreated DC supernatants represent the negative control (CTRL). Results are expressed as ratio of CTRL \pm SEM. (a) TNF-a; (b) IL-6; (c) IL-8; (d) IL-10. - $p \leq 0.05$ to HK/Control; ${ }^{* *} p<0.01,{ }^{*} p \leq 0.05$ to LPS.

As far as the anti-inflammatory cytokine is concerned, HK/Control, HK/NE, or $\mathrm{HK} / 5 \mathrm{HT}$ booster levels of IL-10 are in a way similar to LPS stimulation. HK/NE seems to decrease, and HK/5HT apparently enhances IL-10 production compared to HK/Control stimulation, although the difference is not significant. An additive-like pattern of IL-10 production was observed with the simultaneous stimulation of LPS with HK/Control, HK/NE, or HK/5HT (Figure 5d).

\subsection{In Silico Analyses of a Putative Sensor}

Using the whole genomic sequence data, we screened E. faecium NCIMB10415 for a sensor homologous to QseC, the E. coli adrenergic sensor, and VicK (Walk) from $E$. faecalis [21]. Based on Prokka annotation, we identified a protein sequence annotated as "Sensor histidine kinase WalK". BLASTP with QseC from E. coli K12 strain indicated 29\% identity and $49 \%$ similarity values.

Multiple sequence alignment confirmed that VicK (WalK) from E. faecium NCIMB10415 was conserved compared to similar sequences from E. faecalis strains (Figure 6). Interestingly, two indels were observed at positions $-70 \mathrm{~N}$ and $-140 \mathrm{D}$ by comparison to the E. faecalis sequences. 

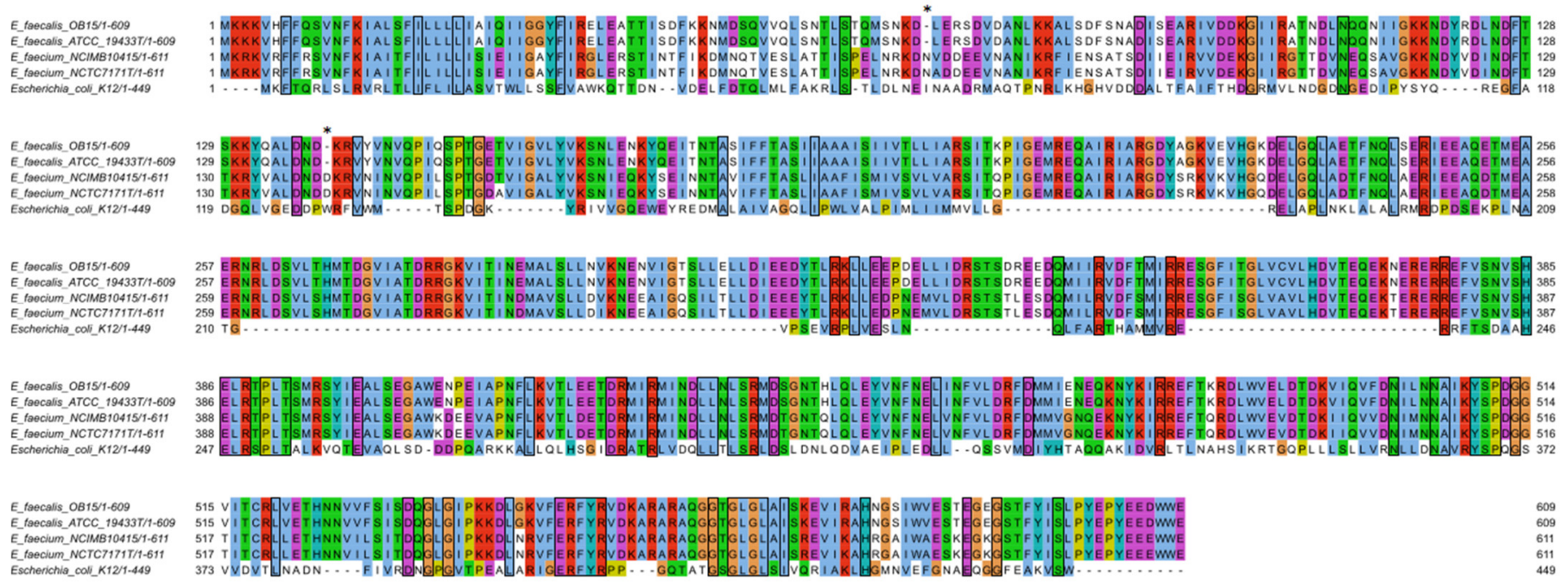

Figure 6. Multiple sequence alignment of E. faecium NCIMB10415's VicK (WalK) amino acid sequence with QseC from E. coli strain K-12 and similar sequences from E. faecalis and E. faecium. Shared amino acids are boxed. Asterisks indicate indels at positions $-70 \mathrm{~N}$ and $-140 \mathrm{D}$ by comparison to the E. faecalis sequences.

\subsubsection{Structure Modeling}

The analysis with PSIPRED (analysis performed in October 2020), particularly with the MEMSAT-SVM program, showed that the E. faecium NCIMB10415 VicK (WalK) protein consists of two transmembrane regions between amino acids 13 and 33 and between amino acids 181 and 200. The carboxy terminus and the amino terminus were predicted to be in the cytoplasm. Conversely, the sequence between the amino acids 33 and 181 showed to be an extracellular domain, thus representing the region of VicK (WalK) that may interact with the catecholamine ligands (Figure 7). This region will be called VicKex (WalKex) in the manuscript. The analysis with pGenTHREADER and pDomTHREADER - two methods for recognizing and aligning protein sequences—showed significant similarities between the intracellular domain of WalK and several histidine kinases, suggesting its function. Through MODELLER for basic modeling, we aligned the FASTA code of VicKex (WalKex) with the PDB database, and we found a significant alignment with the extracellular domain of sensor histidine kinase YycG from Staphylococcus aureus (PDB code: 5IS1) and with the extracellular receptor domain of the sensor kinase WalK from Staphylococcus aureus (PDB code: $4 \mathrm{YWZ}$ ). We then predicted the 3D structure of VicKex (WalKex) by the homology modeling servers RaptorX, GalaxyWeb, and MODELLER through the alignment with YycG and WalK from S. aureus. The models thus obtained were then analyzed to determine the optimum predictive model for molecular docking.

\subsubsection{Molecular Docking}

A molecular docking investigation was performed using AutoDock 4.2 to see if the E. faecium NCIMB10415 VicK (WalK) putative adrenergic sensor would bind NE, 5HT, and the adrenergic blockers phentolamine and propranolol. Each ligand has a total of 50 conformations, each with a specific number of clusters. However, the intermolecular interaction energy function is not always accurate in predicting the actual binding energy because AutoDock considers the enthalpic binding energy in its search for favorable orientations of torsionally flexible ligands; thus, the cluster with the absolute minimum energy does not always represent the best binding site [47]. As a result, the number of alternative conformations for each cluster, the binding energy, and the residues implicated in the binding were used to choose the optimum potential interactions site. Table 2 and Figure 8 illustrate the amino acids involved in the interaction site for the studied ligands, as well as the structure of E. faecium NCIMB10415's VicK (WalK)'s putative binding pocket. 


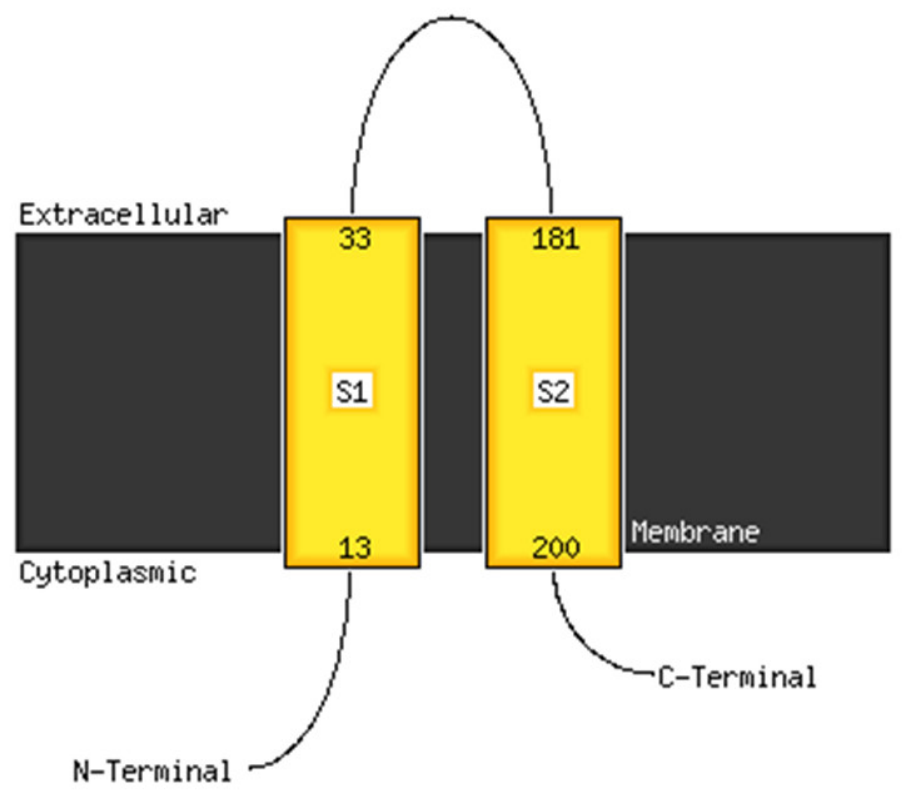

Figure 7. Membrane localization of VicK (WalK) of E. faecium NCIMB10415 using the PSIPred server. An extracellular motif is revealed between the amino acid 33 and 181, which may represent the domain binding catecholamines.
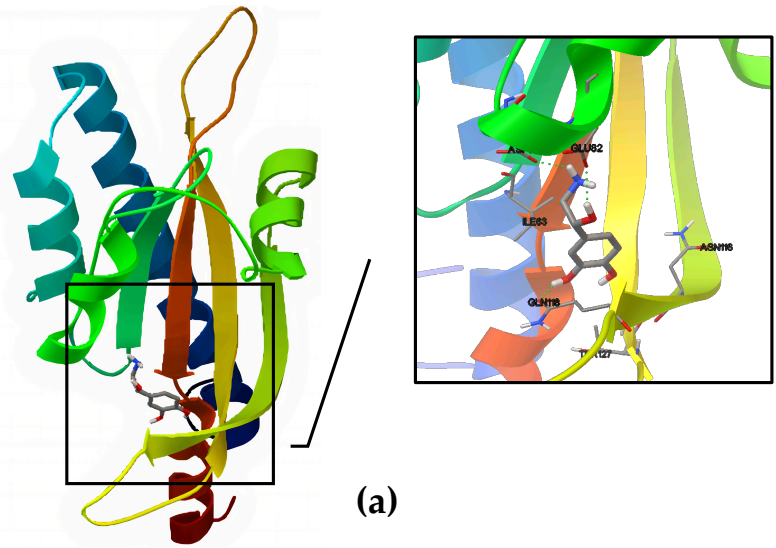

(a)

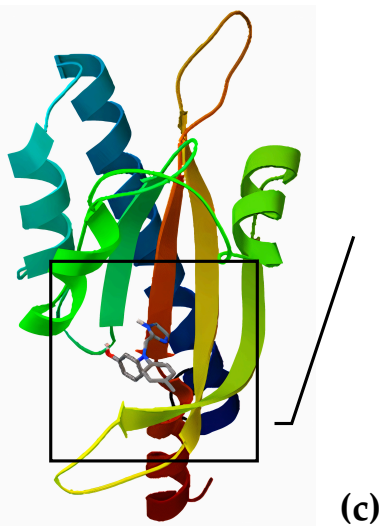

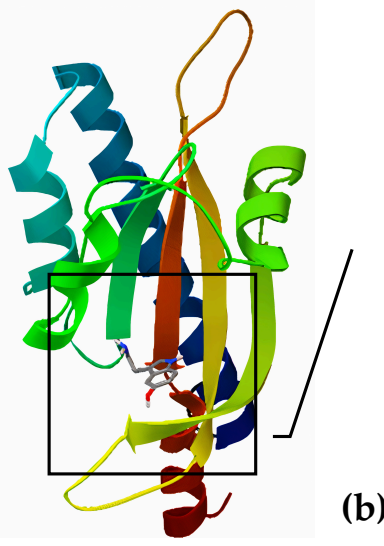

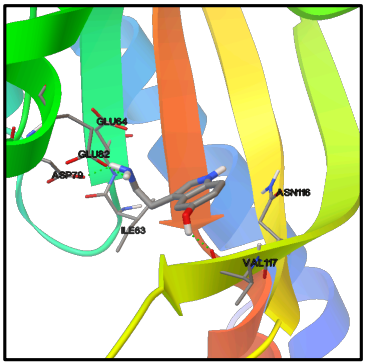

(b)
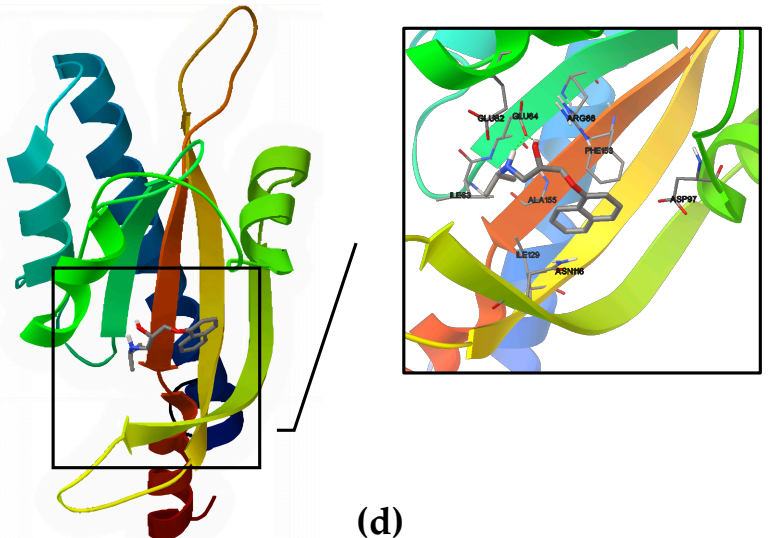

(d)

Figure 8. Docking to the putative structure of VicK (WalK) of E. faecium NCIMB10415: (a) NE; (b) 5HT; (c) phentolamine; (d) propranolol. 
Table 2. The binding energy, number of conformations in the selected cluster, and the amino acids involved in the interaction site of VicK (WalK) for the four ligands tested.

\begin{tabular}{cccc}
\hline Molecule & $\begin{array}{c}\text { Binding Energy } \\
\mathbf{( k c a l / m o l )}\end{array}$ & $\begin{array}{c}\text { Number of } \\
\text { Conformations }\end{array}$ & Amino Acids Involved \\
\hline NE & -6.35 & 7 & $\begin{array}{c}\text { ILE63, ASP78, GLU82, ASN116, } \\
\text { GLN118, THR127 }\end{array}$ \\
\hline 5HT & -6.12 & 5 & $\begin{array}{c}\text { ILE63, GLU64, ASP79, GLU82, } \\
\text { ASN116, VAL117 }\end{array}$ \\
\hline Phentolamine & -3.73 & 2 & $\begin{array}{c}\text { ILE63, GLU64, ASP79, GLU82, } \\
\text { VAL117, GLN118, PHE153, ALA155 }\end{array}$ \\
\hline Propranolol & -5.78 & 4 & $\begin{array}{c}\text { ILE63, GLU64, ARG66, GLU82, ASP97, } \\
\text { ASN116, ILE129, PHE153, ALA155 }\end{array}$ \\
\hline
\end{tabular}

\subsection{Binding Studies-Micro-Scale Thermophoresis}

To complete the in silico study of the putative adrenergic sensor, a Micro-Scale Thermophoresis approach with NE and 5HT was performed to evaluate the binding between E. faecium NCIMB10415's VicK (WalK) and the two hormones. The results obtained by this analysis showed a weak interaction between VicK (WalK) and 5HT, with a dissociation constant $\left(K_{D}\right)$ of $4.50 \pm 0.07 \mathrm{mM}$. In the same way, NE possessed a very low affinity for VicK (WalK), with a detected binding but a $\mathrm{K}_{\mathrm{D}}$ that could not be calculated in our condition (MST buffer and concentration of the used labeled VicK (WalK)).

\section{Discussion}

The elucidation of the complex interplay between bacteria and their host has been the object of several reports in recent decades, especially for the so-called microbiota-gut-brain axis [48]. There is increasing interest in understanding the microbial responses to humanderived molecules. However, most studies explore the effects of host bioactive compounds on opportunistic or pathogenic strains, highlighting the risk of increased pathogenicity under stimulation, and data on commensal or probiotics are scarce to date [21]. This aspect becomes even more critical in enterococci, whose controversial nature has been described above.

The present work intends to shed light on the possible modulation that NE and 5HT, two human hormones abundant in the gut, exert on E. faecium NCIMB10415 relationships with the host, both at the mucosal and at the immune response level. We therefore analyzed how Caco-2/TC7 cells (as a model of intestinal epithelial cells) and DC (as a model of immune cells) react to the treated and untreated probiotic. These two cell types, permanently involved in the interaction with bacteria, are both responsible for homeostasis at the gut level since the former contribute to gut permeability and the latter to inflammatory responses [49]. Finally, we investigated the presence of a putative surface sensor that could mediate these hormones' derived effects.

\subsection{Biofilm, Adhesion and TER}

Adhesion on intestinal epithelial cells is considered an essential trait of probiotics, as adherent bacteria may overcome peristaltic movements and permanently colonize the gut epithelium by forming a biofilm structure where they can persist and exert their positive effects on human health [50]. An adhesion-independent biofilm enhancement was previously assessed by crystal violet staining in this strain after treatment with both NE [22] and 5HT [23]. The confocal microscope analysis of the biomasses validated these findings since the biovolumes, and the maximum and average thickness were higher than those under control conditions. Thus, the capability of both molecules to modulate the persistence in the gut ecological niche was confirmed by the adhesion experiment results, although this activity was more pronounced for NE than 5HT. As far as $5 \mathrm{HT}$ is concerned, our results, although suggesting a moderate increase in adhesion on enterocytes, were 
not statistically significant. The only published evidence of 5HT's effects on bacterial adhesion concerns a 5HT-induced reduction in C. jejuni adhesion to colonic epithelial cells [51]. However, because of the taxonomic distance between these two bacterial models, no definitive considerations can be drawn, and further research is required to clarify this poorly explored field. Conversely, the adhesion-boosting effect induced by NE has been described for several commensals or pathogens such as enterohemorrhagic Escherichia coli, P. aeruginosa, A. hydrophila, and E. faecalis on different cell lines [21,52-54]. In addition, one recent study reported a similar effect induced by NE on two probiotic strains of E. faecalis [21].

Adhesion and persistence of beneficial microbes in the GI tract also affect the intestinal barrier function, potentially benefiting the host. In conjunction with the endothelium, the epithelium creates a physiological barrier that controls transport processes to protect tissue physiology and sustain systemic homeostasis [55]. The well-known "leaky gut syndrome" represents the breaking of this balance that can cause severe inflammatory syndromes, ultimately affecting tissue and organs anatomically very distant from the intestine [56]. The epithelium integrity depends on the intercellular junctions (tight junctions, adherent junctions, and desmosomes), while gap junctions are responsible for cell connectivity [57].

Therefore, we evaluated whether untreated, 5HT- and NE-treated bacterial cells could alter the epithelial barrier integrity and permeability (TER), by measuring electrical resistance through a cellular monolayer, as it mirrors the tight junctions' integrity.

Control E. faecium NCIMB10415 enhanced the TER by about 30\% compared to the negative control (epithelial cells without bacteria), thus confirming the previous results on the same strain by Lodemann and coworkers [58]. This outcome is not unexpected because probiotic bacteria generally protect the epithelial barrier function by triggering mucus production, tight junctions' function, and the immune responses also preventing intestinal cells apoptosis [59]. Furthermore, a TER increase has been described after enterocyte treatments with many different probiotics such as Streptococcus thermophilus, Lactobacillus acidophilus, Lactobacillus plantarum, E. coli Nissle 1917, and Bifidobacterium infantis. Among them, live S. thermophilus and L. acidophilus increased the TER of HT-29 and Caco-2 cells by inducing the activation of the tight junction's proteins Occludin and Zonula Occludens (ZO)-1 [60], while L. plantarum was shown to trigger the expression of genes related to the tight junction's formation [61]. In addition, E. coli Nissle 1917 stimulated the barrier integrity inducing the expression of ZO-2 proteins [62], while in the secretomes of $B$. infantis, a decreased presence of claudins and increased levels of ZO-1 and occludins via the MAPK pathway were observed [63]. To sum up, the beneficial effects of probiotics on gut integrity can be due either to compounds released in the extracellular compartment or to bacteria surface-adherent proteins. Since we used Caco-2/TC7 cells in close contact with E. faecium NCIMB10415, the beneficial effects observed could be due to surface components (increase of $30 \%$ of initial TER). However, secreted mediators could also play a role because of the long incubation time $(20 \mathrm{~h})$.

Interestingly, pre-treating Enterococcus with $100 \mu \mathrm{M}$ NE and $50 \mu \mathrm{M} 5 \mathrm{HT}$ boosted this beneficial impact (increases of 50 and $60 \%$ of initial TER, respectively). To our knowledge, there are no reports regarding the TER modification induced by human hormones on probiotics, while some studies have been performed on pathogens. NE boosted the damaging effect on the epithelium of several Campylobacter strains such as C. jejuni $[64,65]$, C. coli, and C. fetus subsp. fetus on the tight junctions of T84 cells [65]. Epi increased the detrimental effect of Pseudomonas fluorescens on Caco-2/TC7 monolayers integrity, while 5 HT did not trigger significant effects on it [19]. Thus, we could hypothesize that the hormones abundant in the gut can exert a general stimulating effect on bacteria, whose behavior is ultimately determined by the true nature of the species (pathogen or probiotic). Based on the findings of this research, we can assume that the observed improvement in barrier integrity may be in part related to the increased number of adherent bacteria in the stimulated conditions. 


\subsection{Immune-Targeted Activity}

The gut-associated lymphoid tissue (GALT), which constitutes $70 \%$ of the overall immune system, is one of the most critical barriers to controlling infection and inflammation [27]. Although the contact between gut bacteria and immune cells is not as direct as that with epithelial cells, specific cell types such as dendritic cells (DC) can protrude in the intestinal lumen and sense bacteria. The contact is mediated by TLRs (Toll-like receptors) on the immune cells and MAMP (microbial-associated molecular patterns) on the bacterial surface. Moreover, small molecules (Short Chain Fatty Acids, amino acids) that can translocate across the gut barrier can be used by bacteria as soluble signals to stimulate immune responses [27].

Several studies demonstrated that probiotic bacteria could influence the host's immune system and modulate immune responses [28]. Most microorganisms that are considered probiotics are generally selected from the Lactobacillus or Bifidobacterium genera and have been shown to interact with DC and to induce strain-specific effects. For example, some strains modulate the cytokine production of DC in vitro and induce a regulatory response, while others induce conversely a pro-inflammatory response [66,67]. As far as the genus Enterococcus is concerned, the activation of human and murine DC by E. faecalis has been shown [29]; however, few data are available about the effects of E. faecium on the immune system [30]. The immune-regulating activity of enterococci is an appreciated trait both to counteract infection (immune stimulation) and to control inflammatory bowel syndrome and irritable bowel disease as well as systemic inflammatory pathways (immune modulation) $[68,69]$.

Here, we have evaluated the possible boosting effect that the treatment of E. faecium NCIMB10415 with 5HT and NE can have on its natural capability to modulate immune functions using DC as targets. DC are classified into two stages: immature and mature, based on the expression of soluble mediators or unique surface receptors [70]. Some immune parameters such as DC differentiation, maturation, and interleukin (IL) production were considered. First, we observed that DC stimulated with E. faecium NCIMB10415, grown in the presence or absence of the two hormones, upregulated differentiation, and maturation markers. Therefore, no significant specific activation due to NE and 5HT stimulation was assessed. The quantification of cytokines secreted in cell culture supernatants was the second objective of our immunological study, and we demonstrated that the strain in this study could modify the release of both pro-inflammatory and anti-inflammatory cytokines by DC.

TNF- $\alpha$, IL-6 and IL-8 were studied as pro-inflammatory cytokines, and all the E. faecium NCIMB10415 cultures (HK/Control, HK/NE, and HK/5HT) were able to induce their release from DC, but to a lesser extent than LPS stimulation. While no effect was observed by 5HT treatment, NE seemed to double up the production of TNF- $\alpha\left({ }^{*} p<0.05\right)$. A significant upregulation of TNF- $\alpha$ production in DC challenged with the simultaneous presence of treated and untreated E. faecium NCIMB10415 and LPS was also observed. TNF$\alpha$ is an inflammatory cytokine that is released during acute inflammation and responsible for a variety of signaling events that lead to necrosis or apoptosis [71].

As far as the anti-inflammatory IL-10 is concerned, all E. faecium NCIMB10415's cultures (HK/Control, HK/NE, HK/5HT) can boost its production at a level comparable to that triggered by LPS, although not significantly. Interestingly, cotreatment with both control and 5HT-stimulated E. faecium NCIMB10415 and LPS further enhances the IL10 production $(p<0.01)$. The latter regulates Th1 and Th2 responses by limiting T cell activation to restrict and terminate inflammatory responses [72]. IL-10 has been related to the immune-modulating activity exerted by probiotics in preventing IBDs $[73,74]$. These overall findings indicate that $E$. faecium NCIMB10415 can cause specific patterns of cytokine production, particularly IL-10 and TNF- $\alpha$ as shown for many other probiotic LAB strains on different IS cells $[67,75]$. Furthermore, compared to the Gram-negative-derived LPS, this strain mainly seems to trigger an anti-inflammatory response, even if the pro-inflammatory pathway can also be elicited under NE stimulation. 
It is tempting to speculate about the possible molecules produced by E. faecium NCIMB10415 and involved in immune cells crosstalk. From one side, we can exclude every secreted compound since the cell-free supernatants did not display any activity on DCs. On the other side, surface structures microbe-associated molecular pattern (MAMPS) are well-known targets for DC interaction [27]. Nevertheless, we must consider that all the treated and untreated cells were HK, and therefore proteins should be excluded because thermal denaturation events can damage protein folding, structure, and performance. Cellwall components are probably the best candidates for inducing the modulation observed; however, more detailed research is necessary to shed light on these aspects, considering that hormone treatment does not dramatically affect the strain behavior towards DC.

\subsection{Sensor}

Previous studies have identified or hypothesized the presence of bacterial sensors to host molecules, in particular belonging to the family of the TCS, for human hormones in pathogens $[21,25,76-78]$. These systems include an integral trans-membrane kinase (HPK) that acts as a sensor for the stimulus and phosphorylates, plus a response regulator (RR), which mediates the signaling events resulting in gene transcription and targeted expression of specific phenotypic characters in response [79]. In bacterial pathogens, $E$. coli O157:H7 [25] and Salmonella typhimurium [76], the two-component systems QseBC and QseEF are involved in response to Epi and NE, and other TCSs have been recently identified in Citrobacter rodentium (CpxA—5HT sensor) [78] and in E. faecalis VicKR (WalKR) - putative $\mathrm{NE}$ and Epi sensor [21].

To investigate whether the probiotic strain E. faecium NCIMB10415 possesses a surface receptor responsible for sensing human hormones, we performed both in silico and in vitro studies. A genomic analysis in E. faecium NCIMB10415 genome, to search for QseC (the $E$. coli adrenergic receptor) and its homologs VicK (WalK) from E. faecalis, also allowed the identification of VicK (WalK) in this bacterium as the nearest protein to QseC with $29 \%$ identity and $46 \%$ similarity values. This protein is part of the two-component system VicKR (WalKR) also known in the literature as YycGF. Moreover, the whole proteomic analysis performed by our group [23] on E. faecium NCIMB10415 treated with NE or 5HT highlighted a higher abundance (fold-change of 1.4) of the DNA-binding response regulator VicR (vicR, HMPREF0351_12362) in 5HT-treated bacteria than in control cultures, supporting the idea of the involvement of the VicKR (YycFG) system in 5HT sensing). However, the VicK component of the TCS was missing since, in the proteome analyses, no enrichment for membrane-bound proteins was performed. On the contrary, treatment with NE did not seem to enhance the production of VicR [22].

Modeling of VicKex (WalKex) structure and molecular docking allowed us to study the interaction of this E. faecium NCIMB10415 adrenergic putative sensor with NE and 5HT. Our in silico analysis stands out that NE and 5HT are most likely binding to the receptor, with a free binding energy of -6.35 and $-6.12 \mathrm{kcal} / \mathrm{mol}$, respectively. This value found for the interaction between VicK (WalK) and NE is slightly different than the one previously published for E. faecalis [21]. This can probably be explained by the indels found in $E$. faecium and substitution of some amino acids in the VicK (WalK) sequence, but also by the models used in the different steps of the molecular docking. We also tested the affinity of two adrenoreceptors antagonists: propranolol and phentolamine. Propranolol showed an intermediate affinity to the receptor $(-5.78 \mathrm{kcal} / \mathrm{mol})$. Simultaneously, phentolamine docking showed low binding energy $(-3.73 \mathrm{kcal} / \mathrm{mol})$ and many clusters with only one or two conformations, suggesting a non-specific binding that could modify the binding pocket for NE and 5HT and therefore act as a dose-dependent inhibitor. It is also worth mentioning that nearly the same amino acids are involved in the binding of these four molecules to E. faecium VicK (WalK).

Finally, the MST analysis detected a weak binding between the purified putative sensor and $5 \mathrm{HT}$ with a $\mathrm{K}_{\mathrm{D}}$ of $4.50 \pm 0.07 \mathrm{mM}$. In contrast with the in silico docking data, NE seemed to also possess a low affinity with a non-measurable $\mathrm{K}_{\mathrm{D}}$ in our experimental condition. 
However, some phenotypic changes were detected in the presence of NE, suggesting that this molecule could act through different mechanisms. Two possible hypotheses can support this experimental evidence: (a) NE may enter into the cell via a transport system and elicit its role in the cytoplasm; as a matter of fact, OCT and PMAT-like transports have been reported for other LABs, such as Lactobacillus [80]. (b) NE could trigger its cascade effects by means of an intermediate soluble molecule, as for the NE-AI discovered in $E$. coli [81]. It could be argued that the calculated $\mathrm{K}_{\mathrm{D}}$ for $5 \mathrm{HT}$ is too high to justify binding in vivo. However, it has to be considered that Vick (WalK) is a membrane protein, and therefore it is hydrophobic. For this reason, due to the buffer solution, it could be folded in a way not strictly corresponding to its natural conformation. Therefore, it could be interesting, using the MST approach, to test different buffers and detergents to optimize the experimental setting in the near future.

Several studies have proved a connection between the microbial TCS signaling pathway and bacterial responses to different environmental stimuli. For example, it has been shown that QseC, the TCS analog of (VicK) WalK, in Haemophilus influenzae [82] and Aggregatibacter actinomycetemcomitans [83] controls the biofilm formation. Moreover, WalKR in S. aureus proved to be involved in aggregation and biofilm formation [84] as observed in our previous $[22,23]$ and the present work. Therefore, the 5HT stimulation of E. faecium NCIMB10415 through the WalK signaling pathway could be responsible for activating pathways linked to the enhancement of aggregating properties and biofilm of the treated bacteria.

We can conclude that our in silico and in vitro experiments neither confirm nor contradict the presence of a sensor on the bacterial surface, and most importantly, do not exclude other different mechanisms of action of the hormones. However, we hope that future investigations can fill the gap adding new consistence to this hypothesis. It is also possible that the VicK/WalK receptor differs from the best-known QseC. Future studies may include the crystallization of the sensor, staining of colocalized molecules and sensors and radioactivity labelling of the hormones to see if they exert their function also by penetrating inside the bacteria.

\section{Conclusions}

In the present study, we demonstrated that the human's hormones NE and 5HT improved bacterial biofilm formation and increased the percentage of adhesion, albeit not significantly for $5 \mathrm{HT}$, on Caco-2/TC7 epithelial gut cells, thus promoting longer persistence of E. faecium NCIMB10415 in the host tissues. Furthermore, the TER experiment intended to evaluate gut cell permeability on differentiated cells demonstrated that the stimulation was beneficial, since the treated bacteria increased the host's barrier function significantly more than the control cultures of Enterococcus NCIMB10415.

Interesting results on the interaction between HK bacteria and DCs were also obtained: even if the hormone treatments had no effect on the strain ability to induce DC maturation and differentiation, the production of the pro-inflammatory TNF- $\alpha$ by DCs challenged with NE-treated HK cells was significantly higher than in control conditions. Moreover, the combined action of LPS and both control and NE-treated HK bacteria boosted the production of TNF- $\alpha$, whereas the simultaneous presence of LPS and both control and 5HT-treated bacteria increased that of IL-10. These findings, although preliminary (future investigations with living bacteria or different IS cells are required) represent a good starting point since, to the best of our knowledge, this is the first study describing how human bioactive compounds can change the interaction between bacteria and the IS.

In parallel, the results of the investigation on the putative sensor and the previous proteomics data [23] give a hint on the possibility that the hormones could be sensed by these bacteria through VicK (WalK), a membrane receptor that exerts its effect by activating some stress response pathways, enhancing membrane transport and interactive/adhesive capability. However, we cannot exclude that other TCS present on E. faecium NCIMB10415 could be involved in the physiological effects observed. 
Further studies are required to provide a more comprehensive model for this interkingdom signaling and shed light on the possible transition probiotic/pathogen. Finally, the human gut environment, with its complexities and high inter-individual variability, should be carefully considered to fully determine the indirect beneficial or adverse effect of the bacterial stimulation on the host physiology.

Supplementary Materials: The following are available online at https:/ /www.mdpi.com/article/10 .3390/microorganisms10030487/s1, Figure S1: TER measurements over time.

Author Contributions: All the listed authors have contributed to the research reported in the manuscript. Conceptualization, N.C. and E.P.; Data curation, R.S., F.B., P.-J.R., A.M.B. and O.L.; Formal analysis, R.S., F.B. and P.-J.R.; Funding acquisition, E.P.; Investigation, R.S. and F.B.; Methodology, R.S., F.B. and S.S.; Software, P.-J.R., A.M.B. and O.L.; Supervision, M.G.J.F., T.M., N.C. and E.P.; Validation, S.S.; Visualization, R.S., F.B., A.M.B., O.L. and S.S.; Writing-original draft, R.S. and F.B.; Writing-review and editing, N.C. and E.P. All authors have read and agreed to the published version of the manuscript.

Funding: The present project has been supported by University of Torino (Local research funding ex 60\% 2019-2021, and PhD in Pharmaceutical and Biomolecular XXXIII cycle funding).

Institutional Review Board Statement: Not Applicable.

Informed Consent Statement: Not Applicable.

Data Availability Statement: Not Applicable.

Conflicts of Interest: The authors declare no conflict of interest.

\section{References}

1. Franz, C. Enterococci in Foods-A Conundrum for Food Safety. Int. J. Food Microbiol. 2003, 88, 105-122. [CrossRef]

2. Hanchi, H.; Mottawea, W.; Sebei, K.; Hammami, R. The Genus Enterococcus: Between Probiotic Potential and Safety Concerns-An Update. Front. Microbiol. 2018, 9, 1791. [CrossRef]

3. Bondi, M.; Laukova, A.; de Niederhausern, S.; Messi, P.; Papadopoulou, C.; Economou, V. Controversial Aspects Displayed by Enterococci: Probiotics or Pathogens? BioMed Res. Int. 2020, 2020, 1-3. [CrossRef] [PubMed]

4. Giraffa, G. Functionality of Enterococci in Dairy Products. Int. J. Food Microbiol. 2003, 88, 215-222. [CrossRef]

5. Hosseini, S.V.; Arlindo, S.; Böhme, K.; Fernández-No, C.; Calo-Mata, P.; Barros-Velázquez, J. Molecular and Probiotic Characterization of Bacteriocin-Producing Enterococcus Faecium Strains Isolated from Nonfermented Animal Foods: Probiotic E. Faecium Strains. J. Appl. Microbiol. 2009, 107, 1392-1403. [CrossRef] [PubMed]

6. Ziadi, M.; Mhir, S.; Dubois-Dauphin, R.; Chambellon, E.; Yvon, M.; Thonart, P.; Hamdi, M. Analysis of Volatile Compounds, Amino Acid Catabolism and Some Technological Properties of Enterococcus Faecalis Strain SLT13 Isolated from Artisanal Tunisian Fermented Milk. BMR J. 2016, 14, 1-12. [CrossRef]

7. Zommiti, M.; Cambronel, M.; Maillot, O.; Barreau, M.; Sebei, K.; Feuilloley, M.; Ferchichi, M.; Connil, N. Evaluation of Probiotic Properties and Safety of Enterococcus Faecium Isolated From Artisanal Tunisian Meat “Dried Ossban”. Front. Microbiol. 2018, 9, 1685. [CrossRef]

8. Baccouri, O.; Boukerb, A.M.; Farhat, L.B.; Zébré, A.; Zimmermann, K.; Domann, E.; Cambronel, M.; Barreau, M.; Maillot, O.; Rincé, I.; et al. Probiotic Potential and Safety Evaluation of Enterococcus Faecalis OB14 and OB15, Isolated From Traditional Tunisian Testouri Cheese and Rigouta, Using Physiological and Genomic Analysis. Front. Microbiol. 2019, 10, 881. [CrossRef]

9. Franz, C.M.A.P.; Huch, M.; Abriouel, H.; Holzapfel, W.; Gálvez, A. Enterococci as Probiotics and Their Implications in Food Safety. Int. J. Food Microbiol. 2011, 151, 125-140. [CrossRef]

10. Pessione, A.; Lamberti, C.; Cocolin, L.; Campolongo, S.; Grunau, A.; Giubergia, S.; Eberl, L.; Riedel, K.; Pessione, E. Different Protein Expression Profiles in Cheese and Clinical Isolates of Enterococcus Faecalis Revealed by Proteomic Analysis. Proteomics 2012, 12, 431-447. [CrossRef]

11. Pillar, C.M.; Gilmore, M.S. Enterococcal virulence-Pathogenicity island of E. faecalis. Front. Biosci. 2004, 9, 2335-2346. [CrossRef] [PubMed]

12. Crank, C.; O’Driscoll, T. Vancomycin-Resistant Enterococcal Infections: Epidemiology, Clinical Manifestations, and Optimal Management. IDR 2015, 8, 217. [CrossRef] [PubMed]

13. Ben Braïek, O.; Smaoui, S. Enterococci: Between Emerging Pathogens and Potential Probiotics. BioMed Res. Int. 2019, 2019, 1-13. [CrossRef] [PubMed]

14. Palmer, K.L.; Gilmore, M.S. Multidrug-Resistant Enterococci Lack CRISPR-Cas. mBio 2010, 1, 4. [CrossRef]

15. Laverde Gomez, J.A.; Hendrickx, A.P.A.; Willems, R.J.; Top, J.; Sava, I.; Huebner, J.; Witte, W.; Werner, G. Intra- and Interspecies Genomic Transfer of the Enterococcus Faecalis Pathogenicity Island. PLoS ONE 2011, 6, e16720. [CrossRef] 
16. Manson, J.M.; Hancock, L.E.; Gilmore, M.S. Mechanism of Chromosomal Transfer of Enterococcus Faecalis Pathogenicity Island, Capsule, Antimicrobial Resistance, and Other Traits. Proc. Natl. Acad. Sci. USA 2010, 107, 12269-12274. [CrossRef]

17. Cirrincione, S.; Neumann, B.; Zühlke, D.; Riedel, K.; Pessione, E. Detailed Soluble Proteome Analyses of a Dairy-Isolated Enterococcus Faecalis: A Possible Approach to Assess Food Safety and Potential Probiotic Value. Front. Nutr. 2019, 6, 71. [CrossRef]

18. Hew, C.M.; Korakli, M.; Vogel, R.F. Expression of Virulence-Related Genes by Enterococcus Faecalis in Response to Different Environments. Syst. Appl. Microbiol. 2007, 30, 257-267. [CrossRef]

19. Biaggini, K.; Barbey, C.; Borrel, V.; Feuilloley, M.; Déchelotte, P.; Connil, N. The Pathogenic Potential of Pseudomonas Fluorescens MFN1032 on Enterocytes Can Be Modulated by Serotonin, Substance P and Epinephrine. Arch. Microbiol. 2015, 197, 983-990. [CrossRef]

20. Cambronel, M.; Tortuel, D.; Biaggini, K.; Maillot, O.; Taupin, L.; Réhel, K.; Rincé, I.; Muller, C.; Hardouin, J.; Feuilloley, M.; et al. Epinephrine Affects Motility, and Increases Adhesion, Biofilm and Virulence of Pseudomonas Aeruginosa H103. Sci. Rep. 2019, 9, 2021. [CrossRef]

21. Cambronel, M.; Nilly, F.; Mesguida, O.; Boukerb, A.M.; Racine, P.-J.; Baccouri, O.; Borrel, V.; Martel, J.; Fécamp, F.; Knowlton, R.; et al. Influence of Catecholamines (Epinephrine/Norepinephrine) on Biofilm Formation and Adhesion in Pathogenic and Probiotic Strains of Enterococcus Faecalis. Front. Microbiol. 2020, 11, 1501. [CrossRef] [PubMed]

22. Scardaci, R.; Varese, F.; Manfredi, M.; Marengo, E.; Mazzoli, R.; Pessione, E. Enterococcus Faecium NCIMB10415 Responds to Norepinephrine by Altering Protein Profiles and Phenotypic Characters. J. Proteom. 2021, 231, 104003. [CrossRef] [PubMed]

23. Scardaci, R.; Manfredi, M.; Barberis, E.; Scutera, S.; Marengo, E.; Pessione, E. Serotonin Exposure Improves Stress Resistance, Aggregation, and Biofilm Formation in the Probiotic Enterococcus Faecium NCIMB10415. Microbiol. Res. 2021, 12, 606-625. [CrossRef]

24. Lesouhaitier, O.; Veron, W.; Chapalain, A.; Madi, A.; Blier, A.-S.; Dagorn, A.; Connil, N.; Chevalier, S.; Orange, N.; Feuilloley, M. Gram-Negative Bacterial Sensors for Eukaryotic Signal Molecules. Sensors 2009, 9, 6967-6990. [CrossRef]

25. Clarke, M.B.; Hughes, D.T.; Zhu, C.; Boedeker, E.C.; Sperandio, V. The QseC Sensor Kinase: A Bacterial Adrenergic Receptor. Proc. Natl. Acad. Sci. USA 2006, 103, 10420-10425. [CrossRef]

26. Rasko, D.A.; Moreira, C.G.; Li, D.R.; Reading, N.C.; Ritchie, J.M.; Waldor, M.K.; Williams, N.; Taussig, R.; Wei, S.; Roth, M.; et al. Targeting QseC Signaling and Virulence for Antibiotic Development. Science 2008, 321, 1078-1080. [CrossRef]

27. Mayer, E.A. Gut Feelings: The Emerging Biology of Gut-Brain Communication. Nat. Rev. Neurosci. 2011, 12, 453-466. [CrossRef]

28. Yan, F.; Polk, D.B. Probiotics and Immune Health. Curr. Opin. Gastroenterol. 2011, 27, 496-501. [CrossRef]

29. Molina, M.A.; Díaz, A.M.; Hesse, C.; Ginter, W.; Gentilini, M.V.; Nuñez, G.G.; Canellada, A.M.; Sparwasser, T.; Berod, L.; Castro, M.S.; et al. Immunostimulatory Effects Triggered by Enterococcus Faecalis CECT7121 Probiotic Strain Involve Activation of Dendritic Cells and Interferon-Gamma Production. PLoS ONE 2015, 10, e0127262. [CrossRef]

30. Khalkhali, S.; Mojgani, N. Enterococcus Faecium; a Suitable Probiotic Candidate for Modulation of Immune Responses Against Pathogens. Int. J. Basic Sci. Med. 2017, 2, 77-82. [CrossRef]

31. Scutera, S.; Riboldi, E.; Daniele, R.; Elia, A.R.; Fraone, T.; Castagnoli, C.; Giovarelli, M.; Musso, T.; Sozzani, S. Production and Function of Activin A in Human Dendritic Cells. Eur. Cytokine Netw. 2008, 19, 60-68. [CrossRef] [PubMed]

32. Krueger, F. Trim Galore: A Wrapper Tool Around Cutadapt and FastQC to Consistently Apply Quality and Adapter Trimming to FastQ Files. 2012. Available online: http://www.bioinformatics.babraham.ac.uk/projects/trim_galore/ (accessed on 1 December 2021).

33. Andrews, S. FastQC: A Quality Control Tool for High Throughput Sequence Data. Version 0.11.2. Available online: http: //www.bioinformatics.babraham.ac.uk/projects / fastqc (accessed on 15 November 2020).

34. Wick, R.R.; Judd, L.M.; Gorrie, C.L.; Holt, K.E. Unicycler: Resolving Bacterial Genome Assemblies from Short and Long Sequencing Reads. PLoS Comput. Biol. 2017, 13, e1005595. [CrossRef] [PubMed]

35. Mikheenko, A.; Prjibelski, A.; Saveliev, V.; Antipov, D.; Gurevich, A. Versatile Genome Assembly Evaluation with QUAST-LG. Bioinformatics 2018, 34, i142-i150. [CrossRef] [PubMed]

36. Seemann, T. Prokka: Rapid Prokaryotic Genome Annotation. Bioinformatics 2014, 30, 2068-2069. [CrossRef]

37. Waterhouse, A.M.; Procter, J.B.; Martin, D.M.A.; Clamp, M.; Barton, G.J. Jalview Version 2-A Multiple Sequence Alignment Editor and Analysis Workbench. Bioinformatics 2009, 25, 1189-1191. [CrossRef]

38. McGuffin, L.J.; Bryson, K.; Jones, D.T. The PSIPRED Protein Structure Prediction Server. Bioinformatics 2000, 16, 404-405. [CrossRef]

39. Ko, J.; Park, H.; Heo, L.; Seok, C. GalaxyWEB Server for Protein Structure Prediction and Refinement. Nucleic Acids Res. 2012, 40, W294-W297. [CrossRef]

40. Webb, B.; Sali, A. Comparative Protein Structure Modeling Using MODELLER. Curr. Protoc. Bioinform. 2016, 54, 5.6.1-5.6.37. [CrossRef]

41. Benkert, P.; Künzli, M.; Schwede, T. QMEAN Server for Protein Model Quality Estimation. Nucleic Acids Res. 2009, 37, W510-W514. [CrossRef]

42. Morris, G.M.; Huey, R.; Lindstrom, W.; Sanner, M.F.; Belew, R.K.; Goodsell, D.S.; Olson, A.J. AutoDock4 and AutoDockTools4: Automated Docking with Selective Receptor Flexibility. J. Comput. Chem. 2009, 30, 2785-2791. [CrossRef]

43. Rosay, T.; Bazire, A.; Diaz, S.; Clamens, T.; Blier, A.-S.; Mijouin, L.; Hoffmann, B.; Sergent, J.-A.; Bouffartigues, E.; Boireau, W.; et al. Pseudomonas Aeruginosa Expresses a Functional Human Natriuretic Peptide Receptor Ortholog: Involvement in Biofilm Formation. mBio 2015, 6, e01033-15. [CrossRef] [PubMed] 
44. Elo, S.; Saxelin, M.; Salminen, S. Attachment of Lactobacillus Casei Strain GG to Human Colon Carcinoma Cell Line Caco-2: Comparison with Other Dairy Strains. Lett. Appl. Microbiol. 1991, 13, 154-156. [CrossRef]

45. Chauviere, G.; Coconnier, M.-H.; Kerneis, S.; Fourniat, J.; Servin, A.L. Adhesion of Human Lactobacillus Acidophilus Strain LB to Human Enterocyte-like Caco-2 Cells. J. Gen. Microbiol. 1992, 138, 1689-1696. [CrossRef] [PubMed]

46. Bernet, M.F.; Brassart, D.; Neeser, J.R.; Servin, A.L. Lactobacillus acidophilus LA 1 Binds to Cultured Human Intestinal Cell Lines and Inhibits Cell Attachment and Cell Invasion by Enterovirulent Bacteria. Gut 1994, 35, 483-489. [CrossRef] [PubMed]

47. Nyrönen, T.; Pihlavisto, M.; Peltonen, J.M.; Hoffrén, A.-M.; Varis, M.; Salminen, T.; Wurster, S.; Marjamäki, A.; Kanerva, L.; Katainen, E.; et al. Molecular Mechanism for Agonist-Promoted $\alpha_{2 \mathrm{~A}}$-Adrenoceptor Activation by Norepinephrine and Epinephrine. Mol. Pharmacol. 2001, 59, 1343-1354. [CrossRef]

48. Lyte, M. Microbial endocrinology: A personal journey. In Microbial Endocrinology; Springer: Berlin/Heidelberg, Germany, $2010 ;$ pp. 1-16.

49. Rimoldi, M.; Chieppa, M.; Salucci, V.; Avogadri, F.; Sonzogni, A.; Sampietro, G.M.; Nespoli, A.; Viale, G.; Allavena, P.; Rescigno, M. Intestinal Immune Homeostasis Is Regulated by the Crosstalk between Epithelial Cells and Dendritic Cells. Nat. Immunol. 2005, 6, 507-514. [CrossRef]

50. Saarela, M.; Mogensen, G.; Fondén, R.; Mättö, J.; Mattila-Sandholm, T. Probiotic Bacteria: Safety, Functional and Technological Properties. J. Biotechnol. 2000, 84, 197-215. [CrossRef]

51. Lyte, J.M.; Shrestha, S.; Wagle, B.R.; Liyanage, R.; Martinez, D.A.; Donoghue, A.M.; Daniels, K.M.; Lyte, M. Serotonin Modulates Campylobacter Jejuni Physiology and in Vitro Interaction with the Gut Epithelium. Poult. Sci. 2021, 100, 100944. [CrossRef]

52. Vlisidou, I.; Lyte, M.; van Diemen, P.M.; Hawes, P.; Monaghan, P.; Wallis, T.S.; Stevens, M.P. The Neuroendocrine Stress Hormone Norepinephrine Augments Escherichia Coli O157:H7-Induced Enteritis and Adherence in a Bovine Ligated Ileal Loop Model of Infection. Infect. Immun. 2004, 72, 5446-5451. [CrossRef]

53. Hegde, M.; Wood, T.K.; Jayaraman, A. The Neuroendocrine Hormone Norepinephrine Increases Pseudomonas Aeruginosa PA14 Virulence through the Las Quorum-Sensing Pathway. Appl. Microbiol. Biotechnol. 2009, 84, 763-776. [CrossRef]

54. Dong, Y.; Liu, J.; Pang, M.; Du, H.; Wang, N.; Awan, F.; Lu, C.; Liu, Y. Catecholamine-Stimulated Growth of Aeromonas Hydrophila Requires the TonB2 Energy Transduction System but Is Independent of the Amonabactin Siderophore. Front. Cell. Infect. Microbiol. 2016, 6, 183. [CrossRef] [PubMed]

55. Srinivasan, B.; Kolli, A.R.; Esch, M.B.; Abaci, H.E.; Shuler, M.L.; Hickman, J.J. TEER Measurement Techniques for in Vitro Barrier Model Systems. J. Lab. Autom. 2015, 20, 107-126. [CrossRef] [PubMed]

56. Obrenovich, M. Leaky Gut, Leaky Brain? Microorganisms 2018, 6, 107. [CrossRef] [PubMed]

57. Schneeberger, E.E.; Lynch, R.D. The Tight Junction: A Multifunctional Complex. Am. J. Physiol.-Cell Physiol. 2004, 286, C1213-C1228. [CrossRef] [PubMed]

58. Lodemann, U.; Strahlendorf, J.; Schierack, P.; Klingspor, S.; Aschenbach, J.R.; Martens, H. Effects of the Probiotic Enterococcus Faecium and Pathogenic Escherichia Coli Strains in a Pig and Human Epithelial Intestinal Cell Model. Scientifica 2015, $2015,235184$. [CrossRef]

59. Ohland, C.L.; MacNaughton, W.K. Probiotic Bacteria and Intestinal Epithelial Barrier Function. Am. J. Physiol.-Gastrointest. Liver Physiol. 2010, 298, G807-G819. [CrossRef]

60. Resta-Lenert, S.; Barrett, K.E. Live Probiotics Protect Intestinal Epithelial Cells from the Effects of Infection with Enteroinvasive Escherichia Coli (EIEC). Gut 2003, 52, 988-997. [CrossRef]

61. Anderson, R.C.; Cookson, A.L.; McNabb, W.C.; Park, Z.; McCann, M.J.; Kelly, W.J.; Roy, N.C. Lactobacillus Plantarum MB452 Enhances the Function of the Intestinal Barrier by Increasing the Expression Levels of Genes Involved in Tight Junction Formation. BMC Microbiol. 2010, 10, 316. [CrossRef]

62. Zyrek, A.A.; Cichon, C.; Helms, S.; Enders, C.; Sonnenborn, U.; Schmidt, M.A. Molecular Mechanisms Underlying the Probiotic Effects of Escherichia Coli Nissle 1917 Involve ZO-2 and PKC? Redistribution Resulting in Tight Junction and Epithelial Barrier Repair. Cell. Microbiol. 2007, 9, 804-816. [CrossRef]

63. Ewaschuk, J.B.; Diaz, H.; Meddings, L.; Diederichs, B.; Dmytrash, A.; Backer, J.; Looijer-van Langen, M.; Madsen, K.L. Secreted Bioactive Factors from Bifidobacterium Infantis Enhance Epithelial Cell Barrier Function. Am. J. Physiol.-Gastrointest. Liver Physiol. 2008, 295, G1025-G1034. [CrossRef]

64. Cogan, T.A.; Thomas, A.O.; Rees, L.E.N.; Taylor, A.H.; Jepson, M.A.; Williams, P.H.; Ketley, J.; Humphrey, T.J. Norepinephrine Increases the Pathogenic Potential of Campylobacter Jejuni. Gut 2007, 56, 1060-1065. [CrossRef] [PubMed]

65. Aroori, S.V.; Cogan, T.A.; Humphrey, T.J. Effect of Noradrenaline on the Virulence Properties of Campylobacter Species. Int. J. Microbiol. 2014, 2014, 279075. [CrossRef] [PubMed]

66. Christensen, H.R.; Frøkiaer, H.; Pestka, J.J. Lactobacilli Differentially Modulate Expression of Cytokines and Maturation Surface Markers in Murine Dendritic Cells. J. Immunol. 2002, 168, 171-178. [CrossRef] [PubMed]

67. Meijerink, M.; van Hemert, S.; Taverne, N.; Wels, M.; de Vos, P.; Bron, P.A.; Savelkoul, H.F.; van Bilsen, J.; Kleerebezem, M.; Wells, J.M. Identification of Genetic Loci in Lactobacillus Plantarum That Modulate the Immune Response of Dendritic Cells Using Comparative Genome Hybridization. PLoS ONE 2010, 5, e10632. [CrossRef]

68. Parvez, S.; Malik, K.A.; Ah Kang, S.; Kim, H.Y. Probiotics and Their Fermented Food Products Are Beneficial for Health. J. Appl. Microbiol. 2006, 100, 1171-1185. [CrossRef]

69. Tuohy, K.M.; Probert, H.M.; Smejkal, C.W.; Gibson, G.R. Using Probiotics and Prebiotics to Improve Gut Health. Drug Discov. Today 2003, 8, 692-700. [CrossRef] 
70. Rescigno, M. Intestinal dendritic cells. In Advances in Immunology; Elsevier: Amsterdam, The Netherlands, 2010; Volume 107, pp. 109-138. ISBN 978-0-12-381300-8.

71. Idriss, H.T.; Naismith, J.H. TNF Alpha and the TNF Receptor Superfamily: Structure-Function Relationship(s). Microsc. Res. Tech. 2000, 50, 184-195. [CrossRef]

72. Moore, K.W.; de Waal Malefyt, R.; Coffman, R.L.; O'Garra, A. Interleukin-10 and the Interleukin-10 Receptor. Annu. Rev. Immunol. 2001, 19, 683-765. [CrossRef]

73. Kühn, R.; Löhler, J.; Rennick, D.; Rajewsky, K.; Müller, W. Interleukin-10-Deficient Mice Develop Chronic Enterocolitis. Cell 1993, 75, 263-274. [CrossRef]

74. de Moreno de Leblanc, A.; Del Carmen, S.; Zurita-Turk, M.; Santos Rocha, C.; van de Guchte, M.; Azevedo, V.; Miyoshi, A.; Leblanc, J.G. Importance of IL-10 Modulation by Probiotic Microorganisms in Gastrointestinal Inflammatory Diseases. ISRN Gastroenterol. 2011, 2011, 892971. [CrossRef]

75. Fabersani, E.; Abeijon-Mukdsi, M.C.; Ross, R.; Medina, R.; González, S.; Gauffin-Cano, P. Specific Strains of Lactic Acid Bacteria Differentially Modulate the Profile of Adipokines In Vitro. Front. Immunol. 2017, 8, 266. [CrossRef] [PubMed]

76. Moreira, C.G.; Weinshenker, D.; Sperandio, V. QseC Mediates Salmonella Enterica Serovar Typhimurium Virulence In Vitro and In Vivo. Infect. Immun. 2010, 78, 914-926. [CrossRef] [PubMed]

77. Reading, N.C.; Rasko, D.A.; Torres, A.G.; Sperandio, V. The Two-Component System QseEF and the Membrane Protein QseG Link Adrenergic and Stress Sensing to Bacterial Pathogenesis. Proc. Natl. Acad. Sci. USA 2009, 106, 5889-5894. [CrossRef] [PubMed]

78. Kumar, A.; Russell, R.M.; Pifer, R.; Menezes-Garcia, Z.; Cuesta, S.; Narayanan, S.; MacMillan, J.B.; Sperandio, V. The Serotonin Neurotransmitter Modulates Virulence of Enteric Pathogens. Cell Host Microbe 2020, 28, 41-53.e8. [CrossRef]

79. Stock, A.M.; Robinson, V.L.; Goudreau, P.N. Two-Component Signal Transduction. Annu. Rev. Biochem. 2000, 69, 183-215. [CrossRef]

80. Lyte, M.; Brown, D.R. Evidence for PMAT- and OCT-like Biogenic Amine Transporters in a Probiotic Strain of Lactobacillus: Implications for Interkingdom Communication within the Microbiota-Gut-Brain Axis. PLoS ONE 2018, 13, e0191037. [CrossRef]

81. Lyte, M.; Arulanandam, B.P.; Frank, C.D. Production of Shiga-like Toxins by Escherichia Coli O157:H7 Can Be Influenced by the Neuroendocrine Hormone Norepinephrine. J. Lab. Clin. Med. 1996, 128, 392-398. [CrossRef]

82. Ünal, C.M.; Singh, B.; Fleury, C.; Singh, K.; Chávez de Paz, L.; Svensäter, G.; Riesbeck, K. QseC Controls Biofilm Formation of Non-Typeable Haemophilus Influenzae in Addition to an AI-2-Dependent Mechanism. Int. J. Med. Microbiol. 2012, 302, 261-269. [CrossRef]

83. Novak, E.A.; Shao, H.; Daep, C.A.; Demuth, D.R. Autoinducer-2 and QseC Control Biofilm Formation and In Vivo Virulence of Aggregatibacter Actinomycetemcomitans. Infect. Immun. 2010, 78, 2919-2926. [CrossRef]

84. Dubrac, S.; Boneca, I.G.; Poupel, O.; Msadek, T. New Insights into the WalK/WalR (YycG/YycF) Essential Signal Transduction Pathway Reveal a Major Role in Controlling Cell Wall Metabolism and Biofilm Formation in Staphylococcus Aureus. J. Bacteriol. 2007, 189, 8257-8269. [CrossRef] 